\title{
Dynamics and Structure of Hydration Water on Rutile and Cassiterite Nanopowders Studied by Quasielastic Neutron Scattering and Molecular Dynamics Simulations
}

\author{
E. Mamontov, ${ }^{* \dagger}$ L. Vlcek, ${ }^{\ddagger}$ D. J. Wesolowski, ${ }^{\S}$ P. T. Cummings, ${ }^{\ddagger}$ W. Wang, ${ }^{\prime \prime}$ L. M. Anovitz, ${ }^{\S}$ \\ J. Rosenqvist, ${ }^{\S}$ C. M. Brown, ${ }^{\perp, \#}$ and V. Garcia Sakai ${ }^{\perp, \wedge}$ \\ Spallation Neutron Source, Oak Ridge National Laboratory, Oak Ridge, Tennessee 37831-6475, Department of \\ Chemical Engineering, Vanderbilt University, Nashville, Tennessee 37235-1604, Chemical Sciences Division, \\ Oak Ridge National Laboratory, Oak Ridge, Tennessee 37831-6110, Environmental Sciences Division, Oak \\ Ridge National Laboratory, Oak Ridge, Tennessee 37831-6036, NIST Center for Neutron Research, National \\ Institute of Standards and Technology, Gaithersburg, Maryland 20899-8562, Indiana University Cyclotron \\ Facility, Bloomington, Indiana 47408, and Department of Materials Science and Engineering, University of \\ Maryland, College Park, Maryland 20742-2115
}

Received: November 2, 2006; In Final Form: January 5, 2007

Quasielastic neutron scattering (QENS) experiments carried out using time-of-flight and backscattering neutron spectrometers with widely different energy resolution and dynamic range revealed the diffusion dynamics of hydration water in nanopowder rutile $\left(\mathrm{TiO}_{2}\right)$ and cassiterite $\left(\mathrm{SnO}_{2}\right)$ that possess the rutile crystal structure with the (110) crystal face predominant on the surface. These isostructural oxides differ in their bulk dielectric constants, metal atom electronegativities, and lattice spacings, which may all contribute to differences in the structure and dynamics of sorbed water. When hydrated under ambient conditions, the nanopowders had similar levels of hydration: about $3.5\left(\mathrm{OH} / \mathrm{H}_{2} \mathrm{O}\right)$ molecules per $\mathrm{Ti}_{2} \mathrm{O}_{4}$ surface structural unit of $\mathrm{TiO}_{2}$ and about $4.0\left(\mathrm{OH} / \mathrm{H}_{2} \mathrm{O}\right)$ molecules per $\mathrm{Sn}_{2} \mathrm{O}_{4}$ surface unit of $\mathrm{SnO}_{2}$. Ab initio optimized classical molecular dynamics (MD) simulations of the (110) surfaces in contact with SPC/E water at these levels of hydration indicate three structurally distinct sorbed water layers $\mathrm{L}_{1}, \mathrm{~L}_{2}$, and $\mathrm{L}_{3}$, where the $\mathrm{L}_{1}$ species are either associated water molecules or dissociated hydroxyl groups in direct contact with the surface, $\mathrm{L}_{2}$ water molecules are hydrogen bonded to $L_{1}$ and structural oxygen atoms at the surface, and $L_{3}$ water molecules are more weakly bound. At the hydration levels studied, $\mathrm{L}_{3}$ is incomplete compared with axial oxygen density profiles of bulk SPC/E water in contact with these surfaces, but the structure and dynamics of $\mathrm{L}_{1}-\mathrm{L}_{3}$ species are remarkably similar at full and reduced water coverage. Three hydration water diffusion components, on the time scale of a picosecond, tens of picoseconds, and a nanosecond could be extracted from the QENS spectra of both oxides. However, the spectral weight of the faster components was significantly lower for $\mathrm{SnO}_{2}$ compared to $\mathrm{TiO}_{2}$. In $\mathrm{TiO}_{2}$ hydration water, the more strongly bound $\mathrm{L}_{2}$ water molecules exhibited slow (on the time scale of a nanosecond) dynamics characterized by super-Arrhenius, "fragile" behavior above $220 \mathrm{~K}$ and the dynamic transition to Arrhenius, "strong" behavior at lower temperatures. The more loosely bound $\mathrm{L}_{3}$ water molecules in $\mathrm{TiO}_{2}$ exhibited faster dynamics with Arrhenius temperature dependence. On the other hand, the slow diffusion component in $\mathrm{L}_{2}$ hydration water on $\mathrm{SnO}_{2}$, also on the time scale of a nanosecond, showed little evidence of super-Arrhenius behavior or the "fragile"-to-"strong" transition. This observation demonstrates that the occurrence of super-Arrhenius dynamic behavior in surface water is sensitive to the strength of interaction of the water molecules with the surface and the distribution of surface water molecules among the different hydration layers. Analysis of energy transfer spectra generated from the molecular dynamics simulations shows fast and intermediate dynamics in good agreement with the QENS time-of-flight results. Also demonstrated by the simulation is the fast (compared to $1 \mathrm{~ns}$ ) exchange between the water molecules of the $\mathrm{L}_{2}$ and $\mathrm{L}_{3}$ hydration layers.

\section{Introduction}

Water species are ubiquitous on metal oxide surfaces exposed to humid environments. In addition to associatively or disso-

\footnotetext{
*E-mail: mamontove@ornl.gov. Phone: (865) 574-5109. Fax: (865)

† Spallation Neutron Source, Oak Ridge National Laboratory.

$\doteqdot$ Vanderbilt University.

$\S$ Chemical Sciences Division, Oak Ridge National Laboratory.

"Environmental Sciences Division, Oak Ridge National Laboratory.

$\perp$ National Institute of Standards and Technology.

\# Indiana University Cyclotron Facility.

$\wedge$ University of Maryland.
} 574-6080. ciatively chemisorbed water that saturates the coordination of surface cations, additional layers of water molecules are chemior physisorbed and display varying degrees of deviation from bulk water structure and dynamics, depending on the nature of the oxide substrate. ${ }^{1,2}$ In oxide nanopowders $(5-10 \mathrm{~nm})$ characterized by high surface area, adsorbed water exerts a great influence on properties of the oxide. ${ }^{3}$ The exceptionally large incoherent neutron scattering cross-section of hydrogen compared to other elements makes neutron scattering an attractive technique to study the dynamics of surface water. For anhydrous oxides of most metals, the incoherent signal is dominated by 
scattering from one or more monolayers of adsorbed surface water, depending on the relative humidity and the surface area of the oxide phase.

Quasielastic neutron scattering (QENS) is very well suited for studying the mobility of water molecules and has been applied to a great variety of water-containing matrices, both organic and inorganic. However, until recently the dynamics of oxide surface water has received almost no attention from QENS. Studies of dynamics of monolayers of surface water in zinc and chromium oxides ${ }^{4,5}$ were rare exceptions. Recently, we performed a series of QENS studies of surface water mobility in zirconium and cerium oxides. ${ }^{6-8}$ We hypothesized that different types of surface water characterized by qualitatively different dynamics could be distinguished using neutron spectrometers with different energy resolution and dynamic range. The water molecules in direct contact with the hydroxylated surface exhibited "slow", super-Arrhenius-type dynamics that shared common features, such as the fragile-to-strong dynamic transition at low temperatures, with bulk-like (that is, nonsurface) water in confinement. On the other hand, the water molecules of the outer hydration layer seemed to exhibit "fast", Arrhenius-type dynamics due to motions more similar to surface jump diffusion than relaxational translational diffusion in bulk water.

In the experiment reported here, we have probed the different time scales of surface water dynamics in two nanopowder oxides, $\mathrm{TiO}_{2}$ and $\mathrm{SnO}_{2}$, each consisting of 5-10 nm individual particles with very well developed (110) surfaces of the rutile crystal structure and both exposed to the same laboratory atmosphere (approximately $23{ }^{\circ} \mathrm{C}$ and $80 \%$ relative humidity) prior to sealing in the sample containers. The classical molecular dynamics simulation model of the (110) surface of both phases in contact with $\mathrm{SPC} / \mathrm{E}$ water ${ }^{1,2}$ has been employed to extract structural and dynamic properties of these oxide surfaces for comparison with the QENS results.

\section{Experimental Section}

2.1. Sample Preparation and Characterization. Rutile ( $\alpha$ $\mathrm{TiO}_{2}$ ) nanocrystals were synthesized by thermohydrolysis of titanium chloride $\left(\mathrm{TiCl}_{4}, 99.9 \%\right.$, Aldrich) under acidic conditions. A clear solution was first prepared by dropwise addition of $11.0 \mathrm{~mL}$ of pure liquid $\mathrm{TiCl}_{4}$ into $100 \mathrm{~mL}$ of $1.0 \mathrm{M} \mathrm{HCl}$ aqueous solution under vigorous stirring at ice-cooled temperature. After storage at $4{ }^{\circ} \mathrm{C}$ for $12 \mathrm{~h}$, the $\mathrm{TiCl}_{4}$ solution was diluted with water to $0.2 \mathrm{M}$ of $\mathrm{TiCl}_{4}$ and then kept at $85{ }^{\circ} \mathrm{C}$ for $12 \mathrm{~h}$. Upon completion of the reaction, the white colloid was transferred into dialysis tubing (SnakeSkin, molecular weight cutoff at 10000, Pierce Chemical Co.) and dialyzed against deionized water (resistivity $\geq 18.0 \mathrm{M} \Omega \cdot \mathrm{cm}$ ) until minimum of conductivity was reached for removal of all free ions. Then the purified colloid was separated by centrifuge and redispersed in water. After sonicating for $3 \mathrm{~h}$, the well-dispersed colloid was heated at $100{ }^{\circ} \mathrm{C}$ for an additional $24 \mathrm{~h}$. Finally, the colloidal nanocrystals were collected by centrifuge and freeze-dried.

Cassiterite $\left(\mathrm{SnO}_{2}\right.$ possessing the tetragonal rutile structure) nanocrystals were produced by hydrolyzing tin tetrachloride $\left(\mathrm{SnCl}_{4}, 99 \%\right.$, Aldrich). A total of $11.7 \mathrm{~mL}$ of pure liquid $\mathrm{SnCl}_{4}$ was first added to $100 \mathrm{~mL}$ of $10^{-3} \mathrm{M} \mathrm{HCl}$ in aqueous solution. Then the solution was diluted with water to $0.1 \mathrm{M}$ of $\mathrm{SnCl}_{4}$ and transferred into a Teflon container inside a steel autoclave. The $\mathrm{SnCl}_{4}$ solution was kept at $150{ }^{\circ} \mathrm{C}$ for $16 \mathrm{~h}$ for the hydrolysis reaction. The resulting white-gray $\mathrm{SnO}_{2}$ colloid was purified by dialysis, redispersed in pure water by sonication, and then kept at $150{ }^{\circ} \mathrm{C}$ for an additional $16 \mathrm{~h}$ before freezedrying.
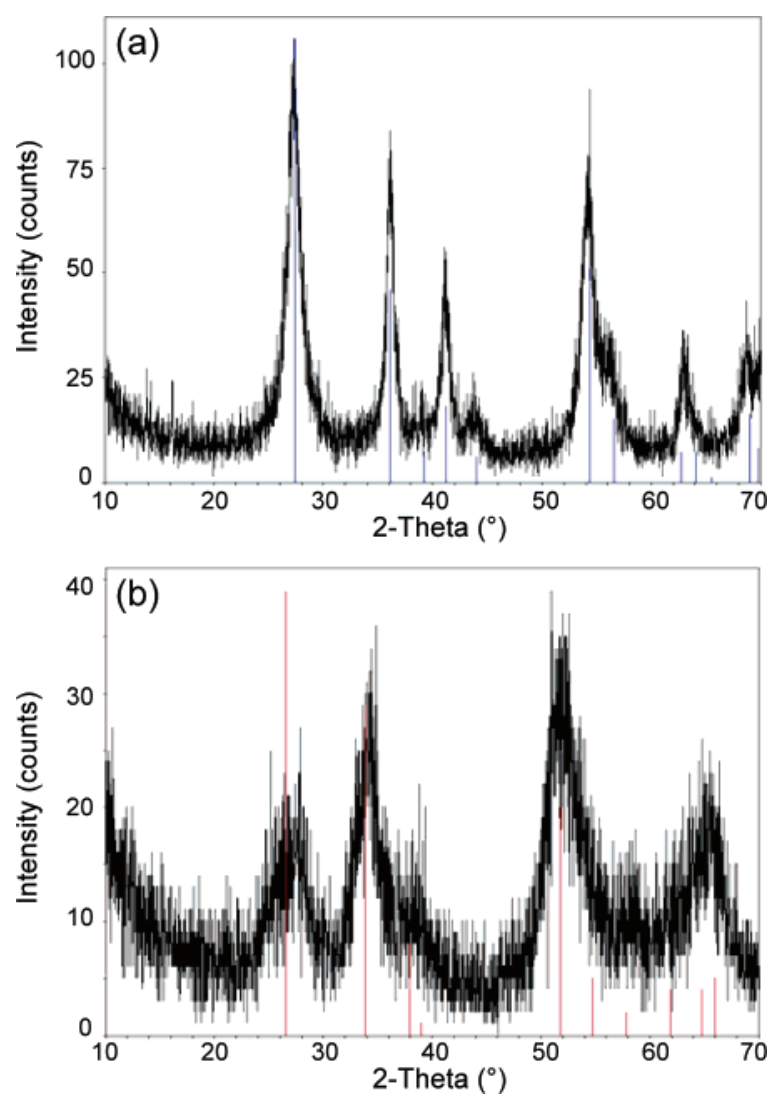

Figure 1. XRD patterns of synthesized (a) $\mathrm{TiO}_{2}$ and (b) $\mathrm{SnO}_{2}$ nanocrystals. The straight lines show standard diffraction positions and relative intensities of bulk rutile and cassiterite powder peaks.

Structures of the synthesized $\mathrm{TiO}_{2}$ and $\mathrm{SnO}_{2}$ were determined by X-ray diffraction (Scintag XDS 2000), indicating the pure tetragonal rutile structure of both $\mathrm{Me}^{\mathrm{IV}} \mathrm{O}_{2}$ phases (the minerals rutile and cassiterite, senso stricto, Figure 1). In this phase, the unit cell parameters of rutile are $a=b=4.594 \AA$ and $c=2.958 \AA$, whereas the corresponding cassiterite parameters are 4.738 and $3.188 \AA$. Morphologies of the synthesized nanocrystals were also investigated using transmission electron microscopy (TEM; Hitachi HF2000), which showed that both $\mathrm{TiO}_{2}$ and $\mathrm{SnO}_{2}$ nanocrystals have rod-like or truncated rod-like habit (Figure 2). The $\mathrm{TiO}_{2}$ nanocrystals have an average length of about $10 \mathrm{~nm}$ with aspect ratios $1: 1$ to $1: 6$, whereas the $\mathrm{SnO}_{2}$ have an average diameter around $4 \mathrm{~nm}$ with aspect ratios $1: 1$ to $1: 2.5$. High-resolution TEM images reveal that 110 faces are dominant for both the $\mathrm{TiO}_{2}$ and $\mathrm{SnO}_{2}$ nanocrystals.

The specific surface area of the nanoparticles was determined using the $\mathrm{N}_{2}$ BET method, yielding $181.3 \mathrm{~m}^{2} / \mathrm{g} \pm 0.3 \mathrm{~m}^{2} / \mathrm{g}$ for $\mathrm{TiO}_{2}$ (theoretical bulk density $4.25 \mathrm{~g} / \mathrm{cm}^{3}$ ) and $155.5 \mathrm{~m}^{2} / \mathrm{g} \pm$ $1.1 \mathrm{~m}^{2} / \mathrm{g}$ for $\mathrm{SnO}_{2}$ (theoretical bulk density $6.99 \mathrm{~g} / \mathrm{cm}^{3}$ ). The charging properties of the nanoparticle surfaces, resulting from protonation/deprotonation of surface oxygen atoms of the truncated crystalline array, were determined using potentiometric titrations, performed at $25{ }^{\circ} \mathrm{C}$ in $0.30 \mathrm{~mol} / \mathrm{kg} \mathrm{NaCl}$ aqueous solution, using a Mettler DL 70 titrator equipped with an Orion Ross 8103 combination electrode (see Figure 3 ). Also included in the figure are the charging curves for $\mathrm{TiO}_{2}$ and $\mathrm{SnO}_{2}$ powders ${ }^{9,10}$ with much larger individual particle sizes (specific surface area of 17 and $7.1 \mathrm{~m}^{2} / \mathrm{g}$, respectively) corresponding to bulk materials. The figure clearly shows that the charging characteristics of the nanoparticles are similar to those of the corresponding macroscopic powders.

Hydration of the dry nanopowders was carried out by allowing both powders to equilibrate with laboratory air 

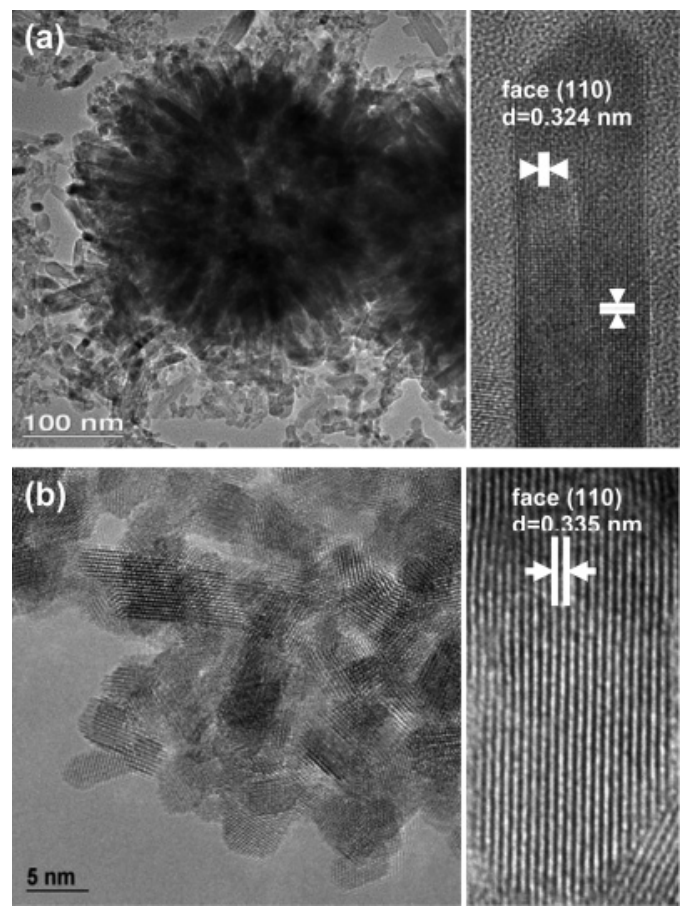

Figure 2. TEM images of synthesized (a) $\mathrm{TiO}_{2}$ and (b) $\mathrm{SnO}_{2}$ nanocrystals.

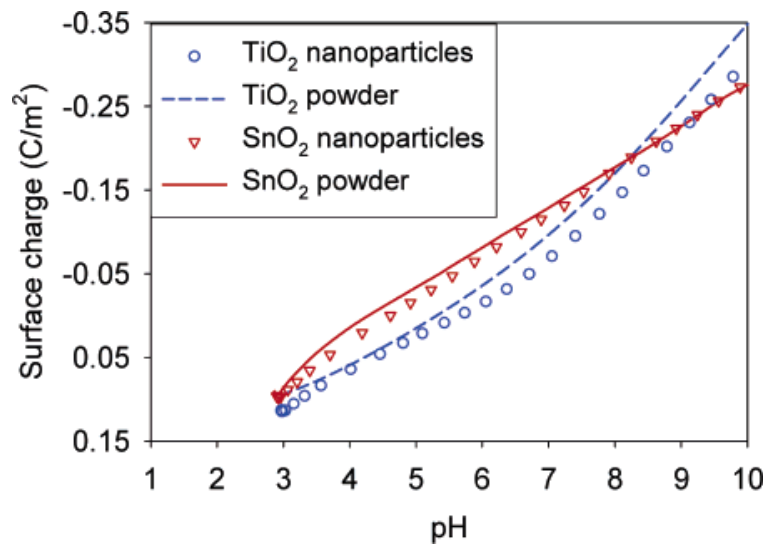

Figure 3. Charging curves for $\mathrm{TiO}_{2}$ and $\mathrm{SnO}_{2}$ nanoparticles (open symbols), compared to charging curves for macroscopic powder samples (solid lines).

(approximately $23{ }^{\circ} \mathrm{C}$ and $80 \%$ relative humidity) for a period of about $24 \mathrm{~h}$ prior to loading in aluminum sample cans, similar to those used previously, ${ }^{6-8}$ with a $1 \mathrm{~mm}$ annular space between the cylindrical outer can and insert walls which was filled with the powder and capped off with a Teflon O-ring prior to sealing the sample cans with indium wire.

Thermal gravimetric analysis (TGA) accompanied by mass spectrometric analysis (MS) of the released components, as well as water sorption/desorption (WS/D) isotherms were obtained using aliquots of the same hydrated powders used in the QENS experiments. TGA/MS was performed at the Institute for Combustion Science and Environmental Technology's Thermal analysis Laboratory at Western Kentucky University. The samples were analyzed using a TA Instruments 2950 TGA interfaced to a Pfeiffer Thermostar Mass Spectrometer by means of a heated capillary transfer line. The samples were heated from room temperature to $1000{ }^{\circ} \mathrm{C}$ at a rate of $10{ }^{\circ} \mathrm{C} / \mathrm{min}$. The capillary transfer line was heated to $200{ }^{\circ} \mathrm{C}$, and the inlet port on the mass spectrometer was heated to $150{ }^{\circ} \mathrm{C}$. The Thermostar unit is based on a quadrupole design and the mass scan ranged

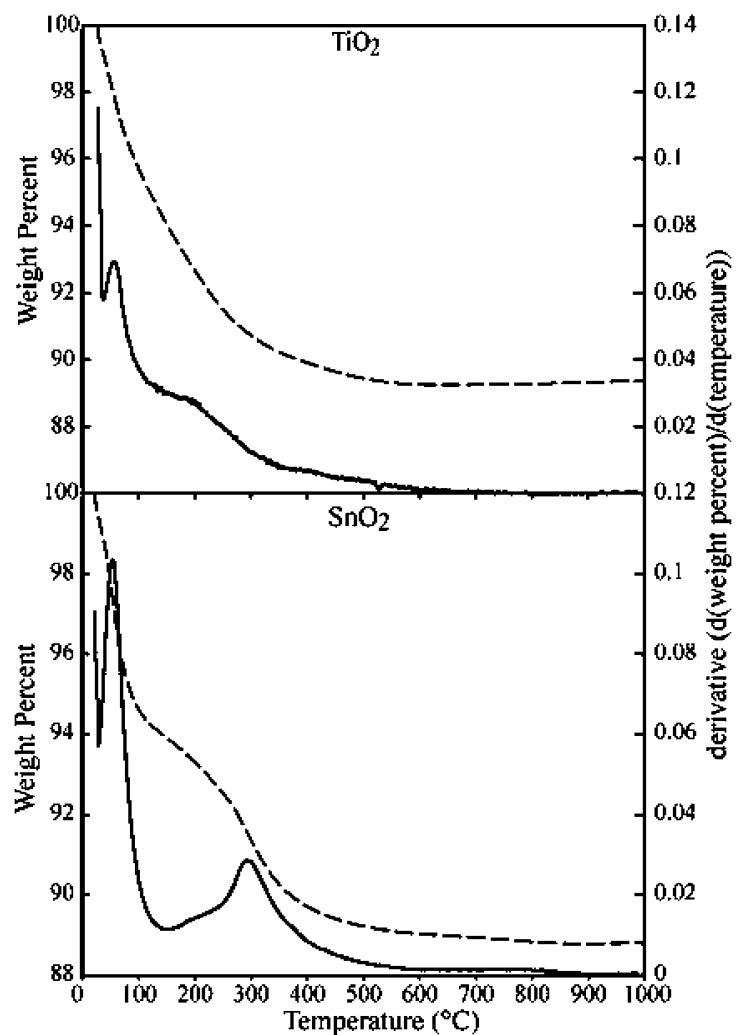

Figure 4. TGA analyses of the $\mathrm{TiO}_{2}$ and $\mathrm{SnO}_{2}$ samples. Dashed lines show the weight loss as a function of temperature. Solid lines show the temperature derivative of the weight loss curves.

from 0 to $200 \mathrm{amu}$. The sample gas from the TGA was ionized at $70 \mathrm{eV}$. The system was operated at a pressure of $1 \times 10^{-5}$ Torr. The experiment took place in nitrogen gas with flow rate of $60 \mathrm{~mL} / \mathrm{min}$. Calibration of water and $\mathrm{CO}_{2}$ contents from the mass spectra were obtained by analyzing samples of $\mathrm{CaC}_{2} \mathrm{O}_{4}$. $\mathrm{H}_{2} \mathrm{O}$ as a standard. The TGA results from these scans are shown in Figure 4, and the results are summarized in Table 1. Both the weight as a function of time and the time derivative are shown.

Two weight loss stages were observed for each sample, characterized by peaks in the derivative curves (Figure 4 ). The maxima for these stages occurred at $61{ }^{\circ} \mathrm{C}$ and $198^{\circ} \mathrm{C}$ for $\mathrm{TiO}_{2}$ and $58{ }^{\circ} \mathrm{C}$ and $301{ }^{\circ} \mathrm{C}$ for $\mathrm{SnO}_{2}$. The presence of a third weight loss stage near $800{ }^{\circ} \mathrm{C}$ is also suggested. Mass spectrographic analysis showed, in both cases, that the first stage consisted almost totally of water loss (although a small amount of $\mathrm{CO}_{2}$ loss was observed in the $\mathrm{TiO}_{2}$ sample), whereas the second stage consisted of both water and $\mathrm{CO}_{2}$. We assume that the $\mathrm{CO}_{2}$ loss from the samples, minor in both cases compared with water loss, but greater for the tin oxide sample, was due to oxidation of adventitious organic carbon, a common feature on surfaces exposed to normal laboratory atmospheres. For both oxides, the measured total weight loss obtained from addition of the mass spectrometric results is slightly lower than that obtained from thermogravimetry. This may, in part, be due to loss of oxygen from the crystalline surfaces, a common feature of rutilestructure oxides at elevated temperatures. Oxygen loss (mass 16) was observed in the mass spectrometric data but was not calibrated. In addition, both samples turned dark during the analysis, a typical reaction of these materials to oxygen loss.

WS/D isotherms were obtained from Quantachrome Instruments, Inc. using a Hydrosorb 1000 water vapor sorption analyzer. Each sample was first outgassed at $150{ }^{\circ} \mathrm{C}$ under vacuum for $16 \mathrm{~h}$, followed by the measurement of isotherms 
TABLE 1: Results of Thermogravimetric and Mass Spectrometric Analyses of the $\mathrm{TiO}_{2}$ and $\mathrm{SnO}_{2} \mathrm{Samples}$

\begin{tabular}{|c|c|c|c|c|c|c|c|c|c|}
\hline \multicolumn{10}{|c|}{ Thermal Gravimetric Results } \\
\hline sample & $\begin{array}{l}\text { initial } \\
\text { weight } \\
\text { sample } \\
(\mathrm{mg})\end{array}$ & $\begin{array}{l}\text { stage }(1) \\
\text { weight loss } \\
\text { (start to } \\
\left.120^{\circ} \mathrm{C}\right) \%\end{array}$ & $\begin{array}{c}\text { stage (1) } \\
\text { weight loss } \\
(\text { start to } \\
\left.120^{\circ} \mathrm{C}\right), \mathrm{mg}\end{array}$ & $\begin{array}{c}\text { max. temp. } \\
\text { stage (1) }\end{array}$ & $\begin{array}{c}\text { stage (2) } \\
\text { weight loss } \\
\left(120-1000^{\circ} \mathrm{C}\right), \\
\%\end{array}$ & $\begin{array}{c}\text { stage }(2) \\
\text { weight loss } \\
\left(120-1000{ }^{\circ} \mathrm{C}\right), \\
\mathrm{mg}\end{array}$ & $\begin{array}{c}\text { max. temp. } \\
\text { stage (2) }\end{array}$ & $\begin{array}{c}\text { residue, } \\
\%\end{array}$ & $\begin{array}{c}\text { total } \\
\text { weight } \\
\text { loss } \%\end{array}$ \\
\hline $\mathrm{TiO}_{2}$ & 15.41 & 4.95 & 0.763 & 61 & 5.71 & 0.88 & 198 & 89.31 & 10.69 \\
\hline $\mathrm{SnO}_{2}$ & 17.64 & 5.71 & 1.007 & 58 & 5.52 & 0.974 & 301 & 88.76 & 11.24 \\
\hline
\end{tabular}

Mass Spectrographic Results

\begin{tabular}{|c|c|c|c|c|c|c|c|c|c|}
\hline & \multicolumn{3}{|c|}{ weight loss, stage $1(\mathrm{mg})$} & \multicolumn{3}{|c|}{ weight loss, stage 2 (mg) } & \multicolumn{3}{|c|}{ totals } \\
\hline & $\mathrm{H}_{2} \mathrm{O}$ & $\mathrm{CO}_{2}$ & total & $\mathrm{H}_{2} \mathrm{O}$ & $\mathrm{CO}_{2}$ & total & $\mathrm{H}_{2} \mathrm{O}$ & $\mathrm{CO}_{2}$ & overall \\
\hline $\mathrm{TiO}_{2}(\mathrm{mg})$ & 0.777 & 0 & 0.777 & 0.524 & 0.104 & 0.628 & 1.301 & 0.104 & 1.405 \\
\hline $\mathrm{SnO}_{2}(\mathrm{mg})$ & 0.941 & 0.0176 & 0.959 & 0.624 & 0.251 & 0.896 & 1.586 & 0.269 & 1.855 \\
\hline $\mathrm{TiO}_{2}(\%)$ & 5.041 & 0.000 & 5.041 & 3.399 & 0.675 & 4.074 & 8.440 & 0.675 & 9.115 \\
\hline $\mathrm{SnO}_{2}(\%)$ & 5.336 & 0.100 & 5.438 & 3.538 & 1.423 & 5.081 & 8.993 & 1.525 & 10.518 \\
\hline
\end{tabular}

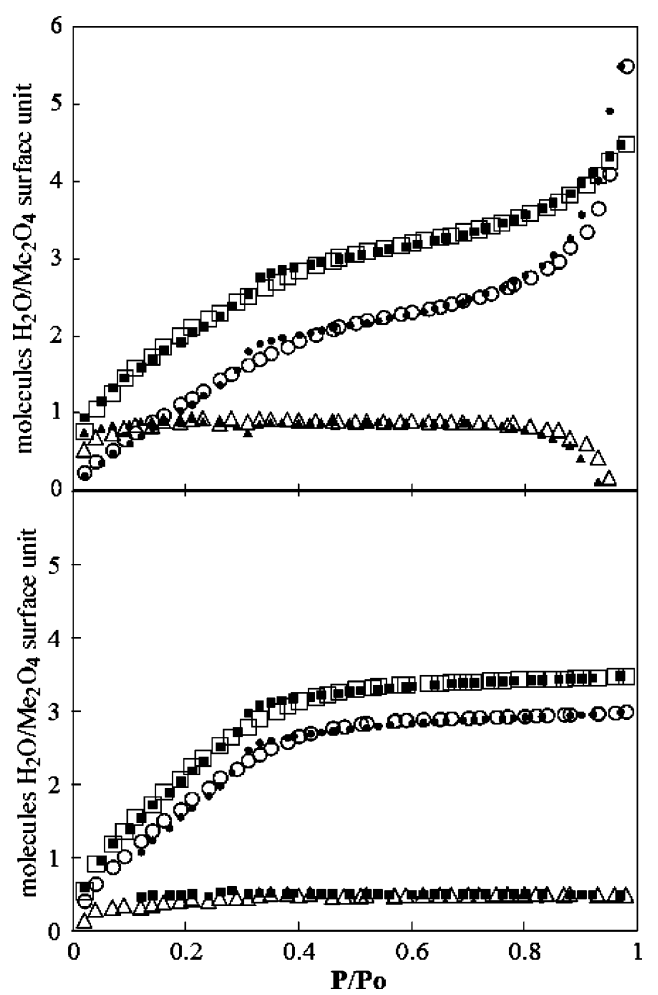

Figure 5. Water adsorption (open symbols) and desorption (solid symbols) data for the $\mathrm{TiO}_{2}$ (upper half) and $\mathrm{SnO}_{2}$ (lower half) samples. Results after outgassing under vacuum at $150^{\circ} \mathrm{C}$ are shown as squares. Results following a second outgassing under vacuum at $25^{\circ} \mathrm{C}$ are shown as circles. The differences between the two curves are shown as triangles.

up to a $P / P_{0}$ value of approximately 0.98 at a bath temperature of $298.4 \mathrm{~K}$. The samples were then re-outgassed at $25^{\circ} \mathrm{C}$ for 2 $\mathrm{h}$, followed by a second adsorption/desorption analysis. The resultant isotherms as a function of $P / P_{0}$ are shown in Figure 5 as molecules of water per $\mathrm{Me}_{2} \mathrm{O}_{4}$ surface unit, which can be converted to weight percent of the dry solid from the surface area of an $\mathrm{Me}_{2} \mathrm{O}_{4}$ surface structural unit (19.2158 and 21.3527 $\AA^{2}$ for the rutile and cassiterite (110) surfaces, respectively) and the BET surface area of each powder. Plotting the data in this manner provides a direct comparison with the MD simulation results discussed below.

It is apparent from the fact that the higher temperature peak in the TGA signal for $\mathrm{SnO}_{2}$ occurs approximately $150{ }^{\circ} \mathrm{C}$ above that for $\mathrm{TiO}_{2}$, that water is significantly more loosely bound to the latter surface. The total weight loss from the TGA signal is, however, complicated by loss of $\mathrm{CO}_{2}$ and oxygen from the
TABLE 2: Hydration Water Contents Based on the Thermogravimetric and Mass Spectrometric Analyses Results in Terms of Molecules of Water per $\mathrm{Me}_{2} \mathrm{O}_{4}$ Surface Unit

\begin{tabular}{lccc}
\hline & stage 1 & stage 2 & totals \\
\hline $\mathrm{TGA}$ results & & & \\
$\mathrm{TiO}_{2}$ & 1.754 & 2.023 & 3.777 \\
$\mathrm{SnO}_{2}$ & 2.621 & 2.534 & 5.155 \\
$\mathrm{mass}_{\mathrm{TiO}}$ & & & \\
$\mathrm{SnO}_{2}$ & 1.786 & 1.204 & 2.990 \\
& 2.449 & 1.624 & 4.128
\end{tabular}

sample, both of which are more significant for the $\mathrm{SnO}_{2}$ sample. The MS results do not provide an absolute measure of water loss, since the ${ }^{16} \mathrm{O}$ evolution spectrum was not calibrated. This latter set of results may, however, serve as a lower bound on the total water content of the samples. Thus, at about $80 \%$ relative humidity, the $\mathrm{TiO}_{2}$ sample appears to have at least 3.0 $\mathrm{H}_{2} \mathrm{O}$ molecules per $\mathrm{Me}_{2} \mathrm{O}_{4}$ surface unit, whereas $\mathrm{SnO}_{2}$ appears to have at least $4.1 \mathrm{H}_{2} \mathrm{O}$ molecules per $\mathrm{Me}_{2} \mathrm{O}_{4}$ surface unit (Table 2).

Water sorption isotherms of both oxides are relatively linear up to a $P / P_{0}$ value of approximately 0.4 , followed by more "normal" sorption behavior at higher $P / P_{0}$ values. Such behavior is typical of combined chemisorption/physisorption isotherms, and suggests that the lower $P / P_{0}$ values were reflecting chemisorption behavior. The second run was therefore performed on each sample in a manner intended to leave the chemisorbed water on the surface. The difference between the two runs (also plotted in Figure 5) is therefore the number of chemisorbed molecules of water per $\mathrm{Me}_{2} \mathrm{O}_{4}$ surface unit that are removed by outgassing at $150{ }^{\circ} \mathrm{C}$. Over most of the $P / P_{0}$ range this was equal to about 0.9 for $\mathrm{TiO}_{2}$, and 0.5 for $\mathrm{SnO}_{2}$.

Both isotherms from the $\mathrm{SnO}_{2}$ sample nicely fit a Langmuir isotherm ${ }^{11}$ above $P / P_{0}=0.3$. Such isotherms typically imply sorption of a single thermodynamic layer of water. Fitting these data yields a thermodynamic "monolayer" for the as-outgassed $\mathrm{SnO}_{2}$ consisting of 3.71 molecules of water per $\mathrm{Sn}_{2} \mathrm{O}_{4}$ surface unit. The upturn in the $\mathrm{TiO}_{2}$ samples at high $P / P_{0}$ can be modeled using a BET isotherm, ${ }^{11}$ which implies adsorption of additional, more loosely bound water. Minor hysteresis upon desorption is apparent in all four isotherms at $P / P_{0} \approx 0.4$, near the boundary between the chemisorption and physisorption parts of the isotherms. Fitting these data to a modified BET isotherm ${ }^{12}$ yields a surface thermodynamic monolayer of 2.44 molecules of water per $\mathrm{Ti}_{2} \mathrm{O}_{4}$ surface unit. However, the continued upturn at higher $P / P_{0}$ values suggests that additional, more weakly bound thermodynamic layers continue to form on the rutile surface as the relative humidity increases. 
The WS/D isotherm data reflect addition of water (only) to samples outgassed at $150{ }^{\circ} \mathrm{C}$, whereas the TGA results suggest that temperatures near $300{ }^{\circ} \mathrm{C}$ are needed to remove the more strongly bound waters on $\mathrm{SnO}_{2}$. Therefore, part of the water actually present on the surface should be missing from the $\mathrm{SnO}_{2}$ isotherms. This is clearly reflected in the results (Figure 5). The differences between the first and second isotherms for each sample suggest that, in the first run $\mathrm{TiO}_{2}$ has chemisorbed approximately one molecule of $\mathrm{H}_{2} \mathrm{O}$ per $\mathrm{Me}_{2} \mathrm{O}_{4}$ surface unit, whereas $\mathrm{SnO}_{2}$ chemisorbed only half a molecule over the same area. At the relative humidity of approximately $80 \%$ at which the samples were hydrated, both samples apparently adsorbed approximately 3.4 to 3.5 molecules of water per $\mathrm{Me}_{2} \mathrm{O}_{4}$ surface unit. However, both the TGA and isotherm data suggest that, although this should be a good approximation of the total water content of the $\mathrm{TiO}_{2}$ sample, this is less than the total amount of water present on the $\mathrm{SnO}_{2}$ surface by approximately 0.5 molecules of water per $\mathrm{Me}_{2} \mathrm{O}_{4}$ surface unit. Thus, the WS/D isotherm data indicate that $\mathrm{TiO}_{2}$ is expected to have approximately 3.5 molecules of water per $\mathrm{Me}_{2} \mathrm{O}_{4}$ surface unit and $\mathrm{SnO}_{2}$ to have approximately 4 molecules of water per $\mathrm{Me}_{2} \mathrm{O}_{4}$ surface unit.

Based on the results discussed above, the values of 3.5 and 4.0 water molecules per $\mathrm{Me}_{2} \mathrm{O}_{4}$ surface unit for $\mathrm{TiO}_{2}$ and $\mathrm{SnO}_{2}$, respectively, were determined as the guidelines for the hydration water coverage in the molecular dynamics simulations that will be described below.

2.2. Neutron Scattering Measurements. QENS experiments were carried out at the National Institute of Standards and Technology (NIST) Center for Neutron Research using the cold neutron time-of-flight Disc Chopper Spectrometer (DCS) ${ }^{13}$ and High Flux Backscattering Spectrometer (HFBS). ${ }^{14}$ Hydrated nanopowders were placed in thin annular aluminum sample holders chosen to ensure greater than $90 \%$ neutron beam transmission through the sample in order to minimize the effects of multiple scattering, sealed with an indium O-ring, and mounted onto closed-cycle refrigerators. The temperature was controlled within $\pm 3 \mathrm{~K}$. The data collected on the DCS at 23 $\mathrm{K}$ (for $\mathrm{TiO}_{2}$ ) and $50 \mathrm{~K}$ (for $\mathrm{SnO}_{2}$ ) and on the HFBS at $5 \mathrm{~K}$ (for both $\mathrm{TiO}_{2}$ and $\mathrm{SnO}_{2}$ ) were used as the sample-dependent resolution functions. In the DCS experiment, the incident neutron wavelength of $\lambda=9.0 \AA$ (incident energy $E_{0}=1.0$ $\mathrm{meV}$ ) was selected. At this incident energy, the high-intensity operation mode of the instrument provides an energy resolution of about $22 \mu \mathrm{eV}$ (full width at half-maximum, fwhm), as determined from the low-temperature data. The data from the detectors covering the range of the scattering vector transfers $0.40 \AA^{-1}<Q<1.20 \AA^{-1}$ (at the elastic channel) have been summed and rearranged to yield 11 spectra with constant-energy binning of the data points for the energy range of $\pm 500 \mu \mathrm{eV}$. At the HFBS, the incident neutron wavelength is varied via Doppler selection about a nominal value of $6.271 \AA\left(E_{0}=2.08\right.$ $\mathrm{meV})$. After scattering from the sample, only neutrons having a fixed final energy of $2.08 \mathrm{meV}$ are measured by the detectors as ensured by Bragg reflection from $\mathrm{Si}$ (111) analyzer crystals. The HFBS was operated with a dynamic range of $\pm 11 \mu \mathrm{eV}$ to provide the best energy resolution and the highest neutron counting rates. With this dynamic range, the sample-dependent instrument resolution function had fwhm of $0.85 \mu \mathrm{eV}$, as determined from the low-temperature data. Due to the overwhelmingly strong small-angle elastic scattering from the nanopowder matrices, the low-angle detectors had to be excluded from the analysis of data obtained at both DCS and HFBS. The HFBS data were thus analyzed for $0.62 \AA^{-1}<Q$
$<1.60 \AA^{-1}$ (at the elastic channel). For both DCS and HFBS measurements, the data for the final analysis were subsequently summed up over the entire corresponding $Q$ ranges, as will be explained below.

2.3. MD Simulation. Microscopic information used for the interpretation of experimental results was obtained from molecular dynamics simulations of water at (110) surfaces of rutile and cassiterite. Water was represented by the SPC/E model, ${ }^{15}$ which is known to accurately reproduce bulk water structure, diffusivity, dielectric properties, and phase behavior over a wide range of temperatures, pressures, and densities. ${ }^{16}$ The interaction of water with metal oxides was modeled by ab initio derived forcefields. ${ }^{17,18}$ Since the rigid SPC/E model is not capable of describing water dissociation, the type of surface (hydroxylated or nonhydroxylated) had to be postulated based on the previous studies. Adsorption of water at rutile and cassiterite surfaces has been studied by experimental methods ${ }^{2,19}$ as well as by ab initio $^{18,20-22}$ and molecular dynamics calculations. ${ }^{1,2}$ Ab initio studies of rutile (110) surface predict that associative adsorption of water molecules is more stable than dissociative, and these conclusions were confirmed by synchrotron X-ray crystal truncation rod (CTR) studies. On the other hand, ab initio calculations predict that dissociative adsorption is more likely than associative at neutral cassiterite surfaces and this conclusion is supported by MD simulations. Thus, we used nonhydroxylated surface for rutile (associative adsorption of the first layer of water) and hydroxylated surface for cassiterite (dissociative adsorption of the first layer of water into surface hydroxyls).

The simulations were performed in the NVT ensemble at $T$ $=300 \mathrm{~K}$. The system consisted of two parallel metal oxide plates separated by more than $40 \AA$, each constructed from a basic $\mathrm{Me}_{4} \mathrm{O}_{8}$ unit replicated six times in the directions parallel to the surface and two times in the perpendicular direction. Fluid phase was composed of 504 water molecules in the rutile system and of 576 water molecules in the cassiterite system, out of which 144 (the first layer) were replaced by 288 surface hydroxyls in the case of $\mathrm{SnO}_{2}$ (the 144 water molecules were split into an $\mathrm{OH}$ group bonded to each bare 5-fold coordinated tin atom and a proton bonded to each bridging oxygen atom on the vacuum-terminated (110) surface $\left.^{1,2}\right)$. This composition resulted in somewhat less than three layers of adsorbed water on each of the metal oxide surfaces, thus reproducing the experimentally observed water coverage of 3.5 for $\mathrm{TiO}_{2}$ and 4.0 for $\mathrm{SnO}_{2}$ in molecules per $\mathrm{Me}_{2} \mathrm{O}_{4}$ surface unit. This surface unit is the area of the rectangle connecting the centers of four nearest bridging oxygen atoms, and the projection of this rectangle perpendicular to the (110) plane encompasses exactly one 5-fold coordinated $\mathrm{Me}^{\mathrm{IV}}$ surface atom and one bridging oxygen atom, in addition to one 6-fold coordinated $\mathrm{Me}^{\mathrm{IV}}$ surface atom and two 3-fold-coordinated surface oxygen atoms. The remaining space of thickness around $25 \AA$ between the plates was filled with water vapor. Long range Coulombic forces were computed using the 3-dimensional Ewald summation with a 2-dimensional correction (EW3DC) ${ }^{23}$ a vacuum gap, required by the method, between the outer sides of the metal oxide plates was about $150 \AA$. The real space cutoff, $r_{\text {cut }}$ was set to 12.66 $\AA$, summation range in the reciprocal space $k_{\max }=5$, and parameter $\alpha=3.09 / r_{\text {cut }}$. A fourth-order predictor corrector method and quaternion formalism was used to integrate the equations of motion in the fluid phase. The atoms in the solid phase were fixed and the motion of surface hydroxyls was computed using the SHAKE algorithm. ${ }^{24}$ The system was equilibrated for more than $1 \mathrm{~ns}$ and production runs spanned 1.0 to $10.0 \mathrm{~ns}$ with the time step of $1.0 \mathrm{fs}$. 


\section{Results and Discussion}

3.1. QENS. The experimental data were fit using the expression

$$
\begin{array}{r}
I(Q, E)=[x(Q) \delta(E)+(1-x(Q)) S(Q, E)+(B E+C)] \otimes \\
R(Q, E)
\end{array}
$$

Here $\delta(E)$ is a delta function centered at zero energy transfer, $x(Q)$ represents the fraction of the elastic scattering, the linear term $(B E+C)$ describes the inelastic background, $R(Q, E)$ is the resolution function, and $S(Q, E)$ is the model scattering function describing the functional dependence of the QENS signal. The elastic signal described by the parameter $x(Q)$ is predominantly due to the scattering from immobile (on the time scale of the measurement) water species chemisorbed on the oxide surfaces. This is because the high molar fraction of water in the hydrated powders along with the dominant incoherent scattering cross-section of hydrogen ensures that the incoherent scattering contribution from the atoms comprising the nanoparticles remains relatively weak compared to that from the protons in the surface water. Even the signal from $\mathrm{Ti}$ atoms, which have much higher incoherent scattering cross-section compared to $\mathrm{Sn}$ and $\mathrm{O}$ atoms, is dwarfed by the scattering from "immobile" protons. The regions of the $Q$ space where the contribution from the nanoparticles to the scattering signal was strong, such as low- $Q$ and Bragg peak positions, were not used in the data analysis.

Since the DCS data showed both broad and narrow quasielastic components, we started analyzing the DCS experimental results using the rotation-translation model previously employed, ${ }^{6}$ for which the QENS broadening is represented using spherical Bessel functions of order $n\left(j_{n}\right)$ by the model scattering function

$$
\begin{aligned}
S(Q, E)=j_{0}^{2}(Q a) \frac{1}{\pi} & \frac{\Gamma(Q)}{E^{2}+\Gamma^{2}(Q)}+ \\
& 3 j_{1}^{2}(Q a) \frac{1}{\pi} \frac{\left[\hbar /\left(3 \tau_{\mathrm{R}}\right)+\Gamma(Q)\right]}{E^{2}+\left[\hbar /\left(3 \tau_{\mathrm{R}}\right)+\Gamma(Q)\right]^{2}}
\end{aligned}
$$

which describes the broad component as originating mainly from isotropic rotational motions of water molecules with gyration radius $a$ and the characteristic time between jumps $\tau_{\mathrm{R}}$ and the narrow component as originating from the unrestricted translational motions of the same water molecules that yields a QENS broadening of $\Gamma(Q)$. For the hydrated $\mathrm{TiO}_{2}$, this model satisfactorily described the data obtained at $345 \mathrm{~K}$, but became less satisfactory and eventually completely unsatisfactory as the temperature was decreased. Furthermore, for the hydrated $\mathrm{SnO}_{2}$, this model proved to be unsatisfactory even at the highest measured temperature of $320 \mathrm{~K}$. To determine the origin of this behavior, we then used a simple model scattering function

$$
S(Q, E)=(1-p(Q)) \frac{1}{\pi} \frac{\Gamma_{1}(Q)}{E^{2}+\Gamma_{1}(Q)^{2}}+p(Q) \frac{1}{\pi} \frac{\Gamma_{2}(Q)}{E^{2}+\Gamma_{2}(Q)^{2}}
$$

where the broad Lorentzian component having a spectral weight of $p(Q)$ originates from faster motions while the narrower Lorentzian component with a spectral weight of $(1-p(Q))$ is due to slower motions. When using eq 3 , no assumption is made as to the character of the faster and slower motions and the fraction of surface water molecules taking part in these motions. Using eq 3, we found that, for the sets of data that could be adequately described using the rotation-translation model represented by eq 2 (in particular, the higher temperature data for the hydrated $\mathrm{TiO}_{2}$ ), the parameter $p(Q)$ increases with the increasing scattering momentum transfer. This is what one would expect should the rotation-translation motion remain valid, because, for a spatially restricted motion such as rotation, the relative spectral weight of the (wider) QENS broadening component with respect to the elastic line grows with $Q$, whereas for unrestricted translational motion the relative spectral weight of the (narrower) QENS broadening component with respect to the elastic line remains unchanged at $100 \%$. In particular, the model scattering function described by eq 2 predicts that a fit with eq 3 should yield $p(Q)=3 j_{1}^{2}(Q a) /\left[j_{0}^{2}(Q a)+\right.$ $\left.3 j_{1}^{2}(Q a)\right]$, that is, the relative spectral weight of the broader Lorentzian should increase with $Q$. We found that the reason why eq 2 yields poor fits for most data sets is because the parameter $p(Q)$ in the fits obtained with eq 3 shows little or no $Q$ dependence. The most likely explanation is that, although the character of the rotational motions remains unchanged through the temperature range of the experiment and between the $\mathrm{TiO}_{2}$ and $\mathrm{SnO}_{2}$ samples, the translational motions become increasingly spatially restricted on the time scale of the measurement at low temperatures and low hydration levels. For a spatially restricted translational motion, the relative spectral weight of the corresponding narrow QENS broadening component with respect to the elastic line is no longer $100 \%$, but increases with $Q$. This offsets the effect of increasing spectral weight of the broad rotational QENS component, thus resulting in a weakly $Q$-dependent $p(Q)$. The fact that the translational diffusion component becomes more spatially restricted may be corroborated by our earlier observations that the QENS broadening due to the translational motions of surface water did not show a pronounced $Q$ dependence at low temperatures ${ }^{7,8}$ as opposed to higher temperatures. ${ }^{6}$

Another evidence for the spatially restricted character of the diffusion process at low temperatures and hydration levels comes from recent specific heat measurements of hydrated rutile, ${ }^{3}$ where the heat capacity of the outer hydration layers was comparable to that of liquid water at room temperature and dropped below that of hexagonal ice for $T<150 \mathrm{~K}$, whereas the heat capacity of the inner hydration layer remained below that of hexagonal ice over the entire temperature range of the measurement. Since the entropic effects introduced by increased translational motion manifest themselves in a change of the heat capacity, the conclusion was that the mobility of the outer hydration layer at low temperatures and of the inner hydration layer at all temperatures was very restricted. Regardless of the spatial characteristics of the translational diffusion process (i.e., spatially restricted vs unrestricted diffusion), the parameter of interest, the characteristic residence time between diffusion jumps, can still be extracted from the width of the QENS broadening. The practical implication is that in the absence of a strong $Q$ dependence the data can be averaged over the entire range of the scattering momentum transfers, thereby greatly improving the statistics.

The $Q$-averaged data obtained on the DCS and HFBS and normalized to the intensity of the corresponding resolution functions are shown in Figures 6 and 7, respectively. One can immediately make several interesting observations. For the DCS data, the hydrated $\mathrm{SnO}_{2}$ spectra show a much lower fraction of QENS signal compared to the hydrated $\mathrm{TiO}_{2}$ spectra. However, this does not apply to the HFBS spectra. These suggest that the fraction of water molecules whose dynamics yield a QENS 


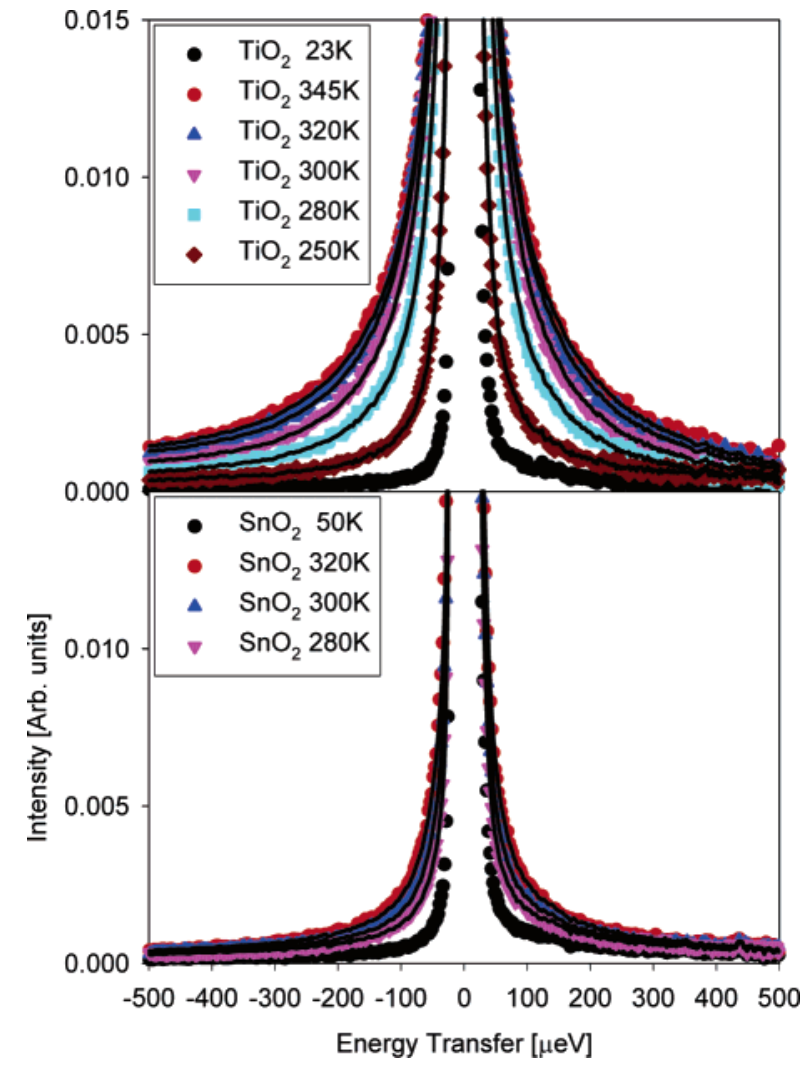

Figure 6. Scattering intensities collected on the DCS and integrated over the range of the scattering vector transfers $0.40 \AA^{-1}<Q<1.20$ $\AA^{-1}$ fit using eqs 1 and 3 .

broadening on the DCS time scale (tens of picoseconds and faster) is significantly lower in hydrated $\mathrm{SnO}_{2}$, relative to the total amount of water contributing to both the elastic and quasielastic signals. Another difference between the hydrated oxides is that the temperature dependence of the hydrated $\mathrm{SnO}_{2}$ DCS spectral broadening appears to be very weak, unlike that of the hydrated $\mathrm{TiO}_{2}$ spectra. For the HFBS data, both samples exhibit temperature-dependent quasielastic scattering of comparable magnitude. Unlike the hydrated $\mathrm{SnO}_{2}$ spectra, which show gradual variation of the QENS signal with temperature, for the hydrated $\mathrm{TiO}_{2}$ spectra, there seems to be a rather abrupt change in the QENS signal between the temperatures of 240 and $220 \mathrm{~K}$.

Also shown in Figures 6 and 7 are the data fits obtained using eqs 1 and 3 . It should be noted that attempts to fit the data using a single Lorentzian component yielded rather poor fits for the DCS data. For the DCS data, the two Lorentzian components were fit independently. On the other hand, for the HFBS data, the width of the broader component was fixed to the values of $\Gamma_{1, \text { DCS }}$ obtained from the DCS fits, and only the narrow component was fit independently. The quality of the two-Lorentzian fits of the HFBS data obtained in this way was improved compared to one-Lorentzian fits.

The effect of the instrument resolution is illustrated in Figure 8 , where the fraction of elastic scattering in the measured signal is plotted as a function of temperature. It should be noted that the water species seen as mobile in the dynamic range of the HFBS appear immobile in a DCS measurement, thus contributing to the DCS elastic signal. On the other hand, much of the dynamics seen in the DCS data is too fast for the HFBS dynamic range, thus contributing to the HFBS background. The fraction of elastic scattering grows as the temperature decreases, indicating that a progressively larger fraction of water molecules

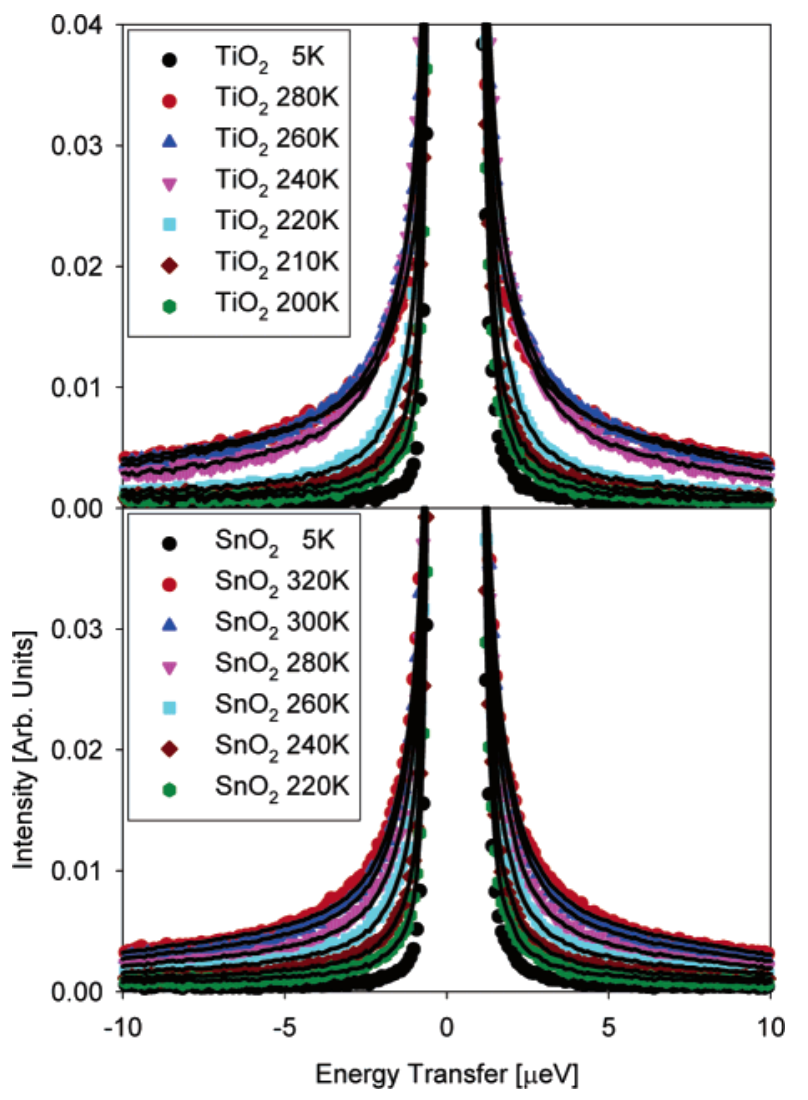

Figure 7. Scattering intensities collected on the HFBS and integrated over the range of the scattering vector transfers $0.62 \AA^{-1}<Q<1.60$ $\AA^{-1}$ fit using eqs 1 and 3 .

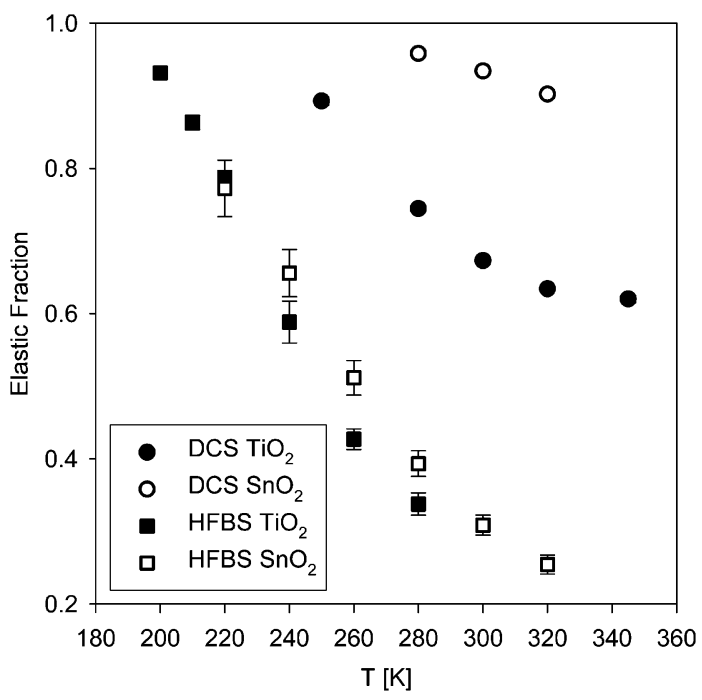

Figure 8. Fraction of elastic scattering, $x(Q)$, obtained from fitting the data using eqs 1 and 3 . The error bars represent one standard deviation.

"freezes" on the time scale of a particular spectrometer. The low number of water molecules with sufficient mobility in hydrated $\mathrm{SnO}_{2}$ results in the apparent elastic fraction in excess of $90 \%$ for the DCS data even at high temperatures, making it impossible to analyze QENS signals in the DCS data obtained from hydrated $\mathrm{SnO}_{2}$ below $280 \mathrm{~K}$. Even for hydrated $\mathrm{TiO}_{2}$, which had a larger number of water molecules with sufficiently fast diffusion dynamics, the QENS signal could not be analyzed below $250 \mathrm{~K}$. Thus, extrapolation of the residence times obtained at higher temperature from the DCS data into the lower temperature region was needed in order to obtain the fixed 


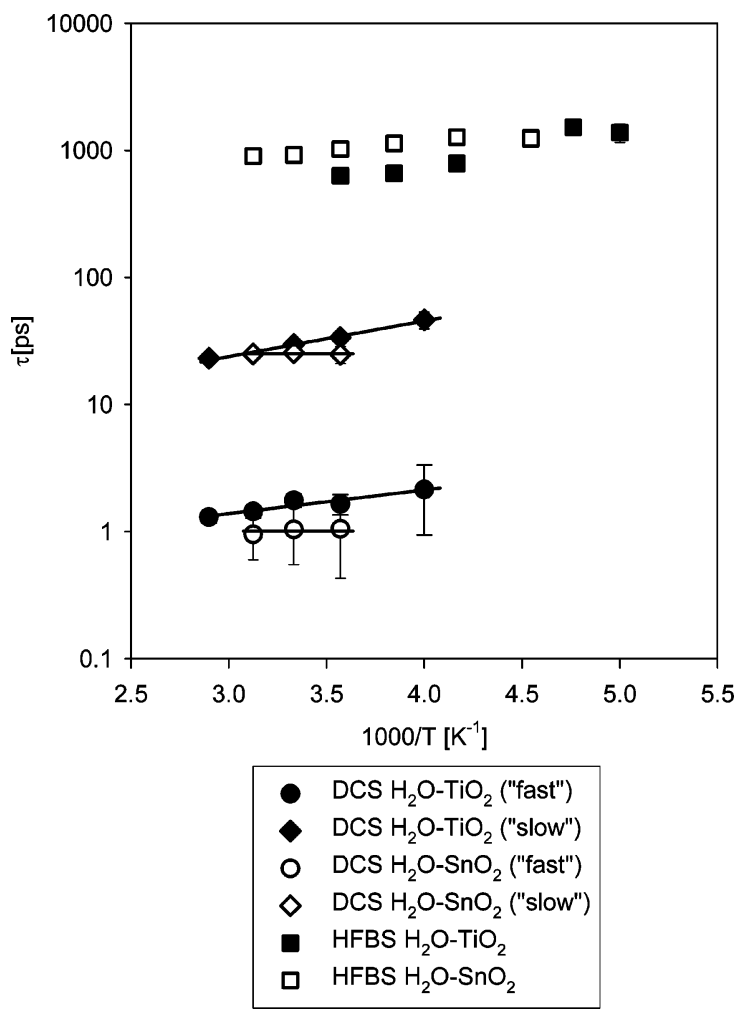

Figure 9. Temperature dependence of the residence times obtained from the DCS and HFBS data. The fastest component is ascribed to a rotational motion, and its relaxation time is calculated from the QENS broadening HWHM, $\Gamma$, as $\tau=\hbar / 3 \Gamma$. The slower components are ascribed to translational motions, and their relaxation times are calculated as $\tau=\hbar / \Gamma$. The data obtained at the DCS are fit with either Arrhenius (for $\mathrm{TiO}_{2}$ ) or temperature-independent (for $\mathrm{SnO}_{2}$ ) laws. The error bars represent one standard deviation.

broader component for the analysis of the HFBS data for both $\mathrm{TiO}_{2}$ and $\mathrm{SnO}_{2}$. Figure 8 corroborates the observation made from Figures 6 and 7 that the main difference between $\mathrm{TiO}_{2}$ and $\mathrm{SnO}_{2}$ is in the fraction of the surface water molecules exhibiting faster dynamics, whereas the difference in the fraction of the molecules showing slow dynamics on a nanosecond time scale is much lower.

The $\log \tau$ vs $1 / T$ plots of the residence times are presented in Figure 9. The residence times (also summarized in Table 3) were calculated from the QENS broadening as $\tau=\hbar / 3 \Gamma_{2}$ for the fast DCS components and $\tau=\hbar / \Gamma_{1}$ for the slow DCS and HFBS components. This is because the fast DCS component was ascribed to the rotational diffusion motion, for which the HWHM of the dominant QENS broadening term equals $\hbar / 3 \tau_{\mathrm{R}}$ (see ref 25 and eq 2). This component is unlikely to originate from a purely translational diffusion process since in such a scenario the residence time between translational jumps would have to be as short as $6 \mathrm{ps}$ even at $250 \mathrm{~K}$. However, the MD results suggest a strong coupling between rotational and translational motions for this diffusion component, as will be discussed below.

As one can see in Figure 9, the residence times for both the fast and slow diffusion components measured on the DCS for hydrated $\mathrm{SnO}_{2}$ show little temperature dependence in the temperature region of 320 to $280 \mathrm{~K}$. The diffusion components observed for the hydrated $\mathrm{TiO}_{2}$ sample appear to obey Arrhenius temperature dependence with activation energies of $(3.6 \pm 0.7)$ $\mathrm{kJ} / \mathrm{mol}$ for the rotational and $(5.4 \pm 0.3) \mathrm{kJ} / \mathrm{mol}$ for the translational component. The activation energy of the rotational component is somewhat lower compared to the value of 4.48
$\mathrm{kJ} / \mathrm{mol}$ determined for hydration water in $\mathrm{ZrO}_{2}$ (ref 6) and substantially lower than the value of $7.74 \mathrm{~kJ} / \mathrm{mol}$ for bulk water. ${ }^{26}$ The rotational diffusion takes place on a picosecond time scale, and slows down by less than a factor of 2 compared to bulk water at room temperature. As typical for a confined environment, the influence of the confinement on the rotational dynamics of water is limited because for localized rotational diffusion motions the dynamics are correlated with a typical hydrogen bond lifetime. On the other hand, the translational dynamics that we observe slows down by more than an order of magnitude at room temperature compared to bulk water. The activation energy of $5.4 \mathrm{~kJ} / \mathrm{mol}$ associated with the translational diffusion component in hydrated $\mathrm{TiO}_{2}$ is much lower compared to the value of $11.38 \mathrm{~kJ} / \mathrm{mol}$ measured for $\mathrm{ZrO}_{2}$ (ref 6). Also the residence time at $300 \mathrm{~K}$ is about $30 \mathrm{ps}$ for $\mathrm{TiO}_{2}$ and about 26 ps for $\mathrm{SnO}_{2}$ vs 40 ps for $\mathrm{ZrO}_{2}$, suggesting that the translational diffusion of hydration water may be more strongly hindered in $\mathrm{ZrO}_{2}$.

Within the resolution and dynamic range of the HFBS, the hydration water in both the $\mathrm{TiO}_{2}$ and $\mathrm{SnO}_{2}$ samples exhibits the slower translational dynamics on the time scale of a nanosecond attributed to more strongly bound hydration water in direct contact with the immobile water species in the layer $\mathrm{L}_{1}\left(\mathrm{OH}\right.$ or $\left.\mathrm{H}_{2} \mathrm{O}\right)$ on the surface, that is, $\mathrm{L}_{2}$ in our notation. It should be noted that the rotational dynamics of this inner hydration layer $\left(\mathrm{L}_{2}\right)$ is likely similar to that of the outer hydration layer $\left(\mathrm{L}_{3}\right)$, which is confirmed by the MD results. Thus, the rotational dynamics cannot be observed within the dynamic range of the HFBS. To investigate the temperature dependence of the slow translational diffusion component in more detail, the HFBS data were replotted in Figure 10 using an expanded scale. One can notice a qualitative difference between the hydrated $\mathrm{TiO}_{2}$ and $\mathrm{SnO}_{2}$ samples. The temperature dependence for the latter can be fit with Arrhenius law with an activation energy of $(2.2 \pm 0.4) \mathrm{kJ} / \mathrm{mol}$. For $\mathrm{TiO}_{2}$, on the other hand, no satisfactory Arrhenius fit can be obtained. The $\log \tau$ vs $1 / T$ plot shows strongly super-Arrhenius behavior, which can be fit with a Vogel-Fulcher-Tammann law, $\tau=\tau_{0} \exp \left(D T_{0} /\left(T-T_{0}\right)\right)$, with a glass transition temperature $T_{0}=(201 \pm 4) \mathrm{K}$ down to about $T=220 \mathrm{~K}$. This is followed by a crossover between 220 and $210 \mathrm{~K}$ very similar to that observed in hydration water in $\mathrm{CeO}_{2}$ at $215 \mathrm{~K}$ and attributed ${ }^{8}$ to the fragile-to-strong transition in hydration water. Such a transition, first detected in water confined in mesoporous silica, ${ }^{27}$ was recently observed in hydration water in lysozyme, ${ }^{28} \mathrm{DNA},{ }^{29}$ and carbon nanotubes. ${ }^{30}$ Thus, the fragile-to-strong transition in hydration water in $\mathrm{TiO}_{2}$ is not unexpected, given its seemingly universal presence in various systems. On the other hand, the apparent absence of such a transition in hydration water in $\mathrm{SnO}_{2}$ indicates that the interaction with the surface, and likely the spatial distribution of the water molecules among the hydration layers, is different for $\mathrm{TiO}_{2}$ and $\mathrm{SnO}_{2}$. This will be discussed in more detail in the following sections.

We have examined whether the temperature dependence of the HFBS data for $\mathrm{SnO}_{2}$ can be fit with a VFT law. The quality of the best VFT fit shown in Figure 10 as a dashed line does not exceed that of the Arrhenius fit. Furthermore, this VFT fit would yield the glass transition temperature $T_{0}=93 \mathrm{~K}$, which is unrealistically low. Therefore, we conclude that fitting the HFBS data for hydrated cassiterite with a VFT law cannot be justified, and thus there is a qualitative difference between the temperature dependence of the slow relaxation time for hydration water in cassiterite (Arrhenius) and rutile (non-Arrhenius). 
TABLE 3: Temperature Dependence of the Relaxation Times (in ps) for Hydration Water in Rutile and Cassiterite Based on Fitting the Data with eqs 1 and 3 and Calculated as $\tau=\hbar / \Gamma^{a}$

\begin{tabular}{|c|c|c|c|c|c|c|}
\hline \multirow[b]{2}{*}{$T, \mathrm{~K}$} & \multicolumn{3}{|c|}{$\mathrm{TiO}_{2}$} & \multicolumn{3}{|c|}{$\mathrm{SnO}_{2}$} \\
\hline & DCS “fast” & DSC "slow" & HFBS & DCS “fast" & DCS "slow" & HFBS \\
\hline 345 & $3.90(0.39)<1.30(0.13)>$ & $23.10(1.40)$ & & & & \\
\hline 320 & $4.32(0.48)<1.44(0.16)>$ & $24.90(1.50)$ & & $2.85(1.05)<0.95(0.35)>$ & $24.99(1.79)$ & $901(27)$ \\
\hline 300 & $5.28(0.63)<1.76(0.21)>$ & $29.68(2.04)$ & & $3.12(1.47)<1.04(0.49)>$ & $25.54(2.59)$ & $918(28)$ \\
\hline 280 & $4.95(0.90)<1.65(0.30)>$ & $33.60(2.19)$ & $630(28)$ & $3.15(1.86)<1.05(0.62)>$ & $24.79(3.81)$ & $1024(37)$ \\
\hline 260 & & & $659(25)$ & & & $1136(55)$ \\
\hline 250 & $6.42(3.60)<2.14(1.20)>$ & $46.41(7.07)$ & & & & \\
\hline 240 & & & 787 (27) & & & $1266(100)$ \\
\hline 220 & & & $1254(72)$ & & & $1233(162)$ \\
\hline 210 & & & $1513(150)$ & & & \\
\hline 200 & & & $1382(227)$ & & & \\
\hline
\end{tabular}

${ }^{a} \Gamma$ is the HWHM of the Lorentzian broadening. The data in angle brackets for the "fast" DCS component represent the relaxation times calculated as $\tau=\hbar / 3 \Gamma$ assuming purely rotational origin of this component. The standard deviation values are shown in parenthesis.

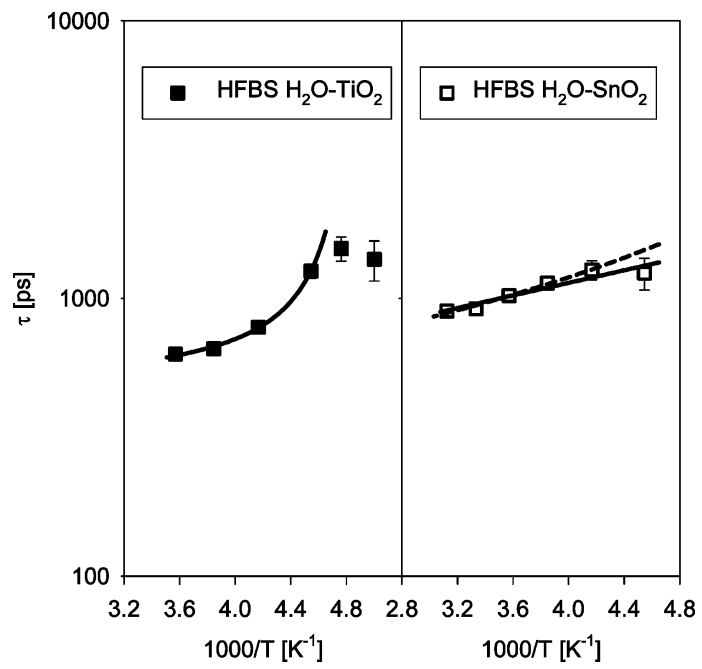

Figure 10. The fits of the temperature dependence of the residence times obtained from the HFBS data with an Arrhenius law for $\mathrm{SnO}_{2}$ (solid line) and a VFT law (at 280, 260, 240, and $220 \mathrm{~K}$ temperature points) for $\mathrm{TiO}_{2}$ (solid line). The fragile-to-strong transition in hydration water manifests itself as a deviation from the VFT fit below $220 \mathrm{~K}$ in the $\mathrm{TiO}_{2}$ data. Also shown is the best VFT fit for $\mathrm{SnO}_{2}$ using 320, $300,280,260$, and $240 \mathrm{~K}$ temperature points (dashed line). The error bars represent one standard deviation.

3.2. MD Simulations. In this study, our ab initio parametrized, classical molecular dynamics models of the (110) crystal surfaces of rutile and cassiterite in contact with bulk SPC/E water $^{1,2}$ are extended to the case of low surface coverage, equivalent to the hydration level observed in the nanopowders used for the QENS experiments presented here. The dominance of the (110) surface on these powders, especially for rutile (Figure 2) justifies this comparison, though necessarily, both powders possess additional surface crystal planes, since (110) is not a closed form. Even in the presence of bulk water, the (110) surfaces of both phases exhibit three distinct surface layers, designated $\mathrm{L}_{1}, \mathrm{~L}_{2}$, and $\mathrm{L}_{3}$, which have unique characteristics relative to bulk water. The (110) surface exposes coplanar, 5-coordinated, and 6-coordinated metal cations and 3-coordinated surface oxygen atoms, as well as 2-coordinated "bridging" oxygen atoms which are each bonded to two 6-fold surface cations and protrude above the surface plane. In water or humid air, a water molecule immediately chemisorbs atop the 5-coordinated surface cation to form a "terminal group", and this water molecule may either remain fully protonated, or dissociate to form a hydroxyl group. In the ideal case, the dissociated proton migrates to the bridging oxygen atom, forming a fully "hydroxylated" or "dissociative" surface, and in the case where
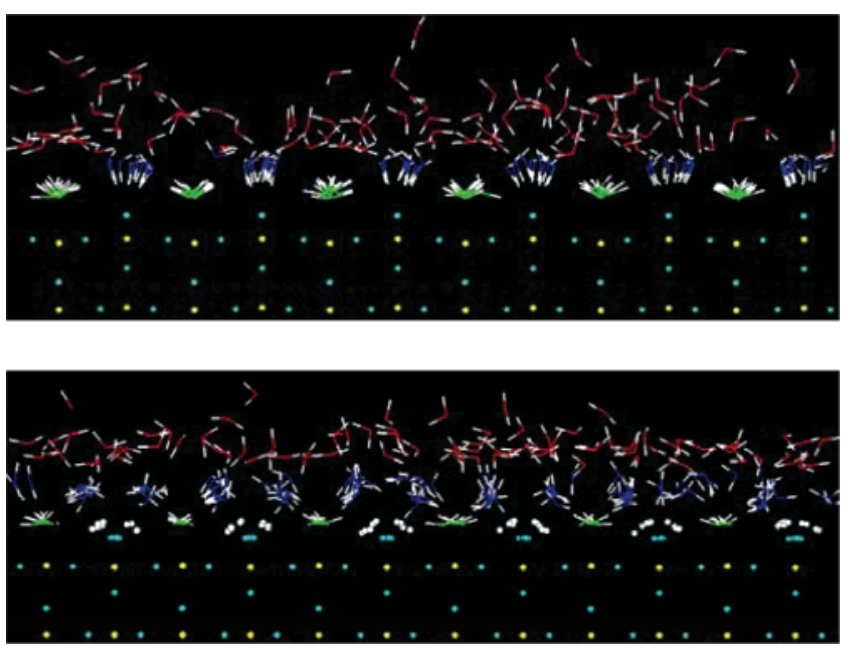

Figure 11. MD snapshots of (a) rutile (top) and (b) cassiterite (bottom) hydrated surfaces. Metal atoms ( $\mathrm{Ti}$ and $\mathrm{Sn}$ ): yellow. Oxygen atoms in oxides: cyan. Oxygen atoms in $\mathrm{L}_{1}$ layer: green. Oxygen atoms in $\mathrm{L}_{2}$ layer: blue. Oxygen atoms in $\mathrm{L}_{3}$ layer: red. Hydrogen: white.

the first chemisorbed water molecule remains intact, the surface is referred to as "nonhydroxylated" or "associative" in the simulations. ${ }^{1,2}$ In either case, this first sorbed layer, designated $\mathrm{L}_{1}$, involves exactly two protons (one water molecule or two hydroxyl groups) per $\mathrm{Me}_{2} \mathrm{O}_{4}$ surface unit. Furthermore, the locations of the terminal and bridging oxygen atoms occupy specific sites dictated by the underlying crystal structure, though the bonds of these oxygen atoms to the surface are free to oscillate and the protons bound to these more or less "tethered" oxygen atoms are themselves tethered at a fixed bond length but are free to move and form hydrogen bonds with other oxygen atoms and water molecules in their vicinity.

The "snapshots" of the structure of the hydration water on the (110) surface of rutile and cassiterite are shown in Figure 11 , and the corresponding axial (surface-normal) density profiles of oxygen atoms as a function of distance away from the $\mathrm{Me}^{\mathrm{IV}}-\mathrm{O}$ surface planes are shown in Figure 12. Also shown in Figure 12 are the axial density profiles for bulk SPC/E water in contact with the (110) surface of rutile and cassiterite. ${ }^{1,2}$ Remarkably, for both rutile and cassiterite, the structure of the near-surface region is essentially the same for the hydration level of our examples compared with the surfaces in contact with bulk water. The presence of the layered structure in the water near the surface, $\mathrm{L}_{1}-\mathrm{L}_{3}$, is evident in both Figures 11 and 12 . $\mathrm{L}_{1}$ forms sharp peaks between 2.0 and $2.2 \AA$. The sharper and narrower peak for cassiterite represents the hydroxyl groups bonded to the 5-fold tin surface atoms but does not include the positions 

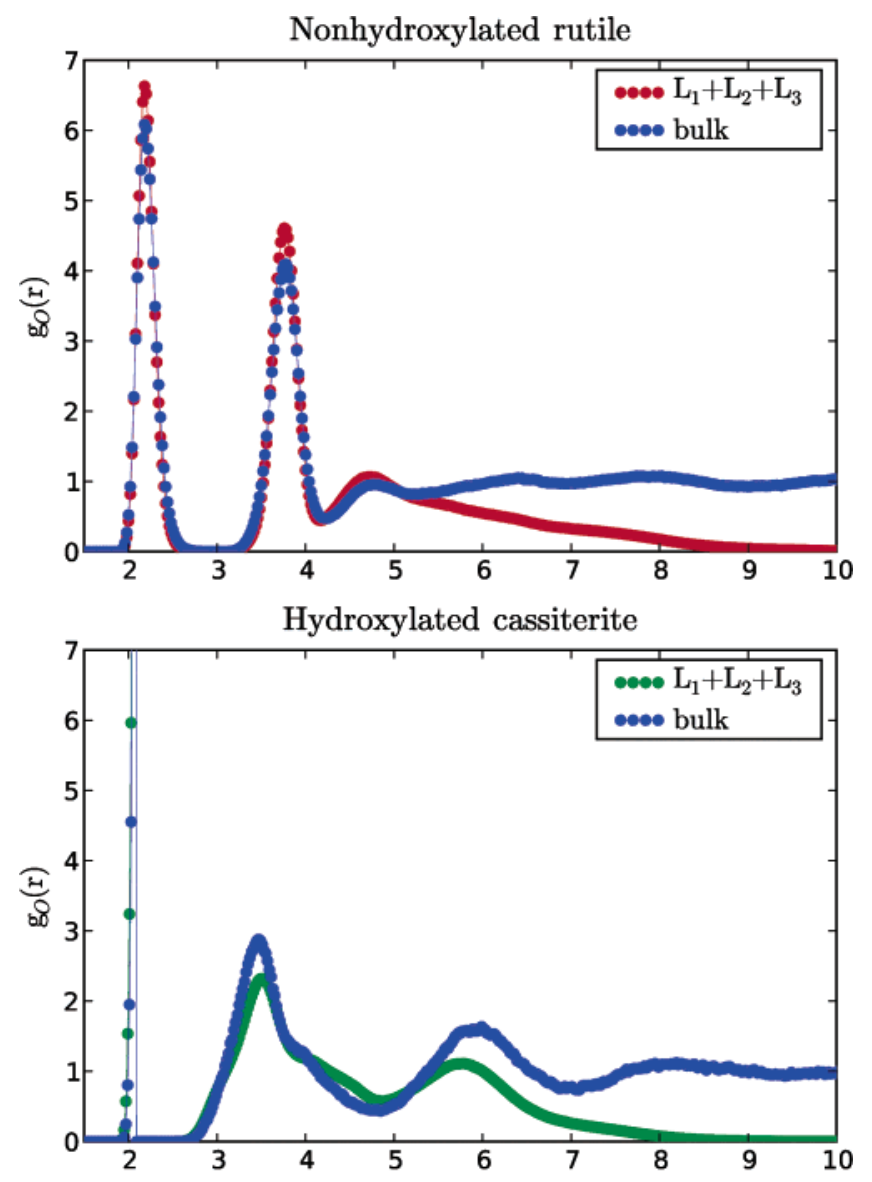

Rutile and cassiterite at $\mathrm{L}_{1}+\mathrm{L}_{2}+\mathrm{L}_{3}$ coverage

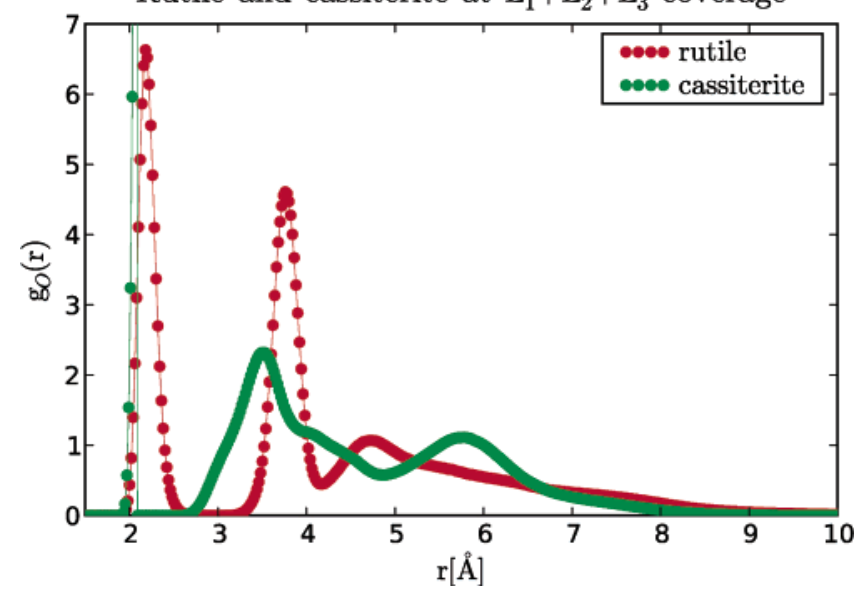

Figure 12. MD results for the axial density profiles of water oxygen atoms near the (110) surface of (a, top) nonhydroxylated rutile, hydration coverage measured in the experiment (red) vs bulk water ${ }^{1,2}$ (blue), (b, middle) hydroxylated cassiterite, hydration coverage measured in the experiment (green) vs bulk water ${ }^{1,2}$ (blue), (c, bottom) comparison of nonhydroxylated rutile (red) and hydroxylated cassiterite (green) for the hydration coverage measured in the experiment.

of the bridging hydroxyl groups, whereas the broader peak for rutile corresponds to associatively adsorbed water molecules atop the 5-fold titanium surface atoms. There are at least two additional peaks in the axial density profiles of each phase, which we define as water molecules sorbed in layers $\mathrm{L}_{2}$ and $L_{3}$, respectively. $L_{2}$ water molecules exhibit specific axial and lateral (surface-parallel) site distribution densities that are influenced both by the underlying crystal structure and strong hydrogen bonding with $\mathrm{L}_{1}$ and $\mathrm{L}_{3}$ species. In distinct contrast, $\mathrm{L}_{3}$ water molecules on the nonhydroxylated surface (rutile)
TABLE 4: MD Results for the Number of Water Molecules Per Surface $\mathrm{Me}_{2} \mathrm{O}_{4}$ Unit in the First Three Layers on the (110) Surface of $\mathrm{TiO}_{2}$ and $\mathrm{SnO}_{2}$ in Contact with Bulk Water and at the Hydration Level of the Experiment ${ }^{a}$

\begin{tabular}{|c|c|c|c|}
\hline system & $\mathrm{L}_{1}$ & $\mathrm{~L}_{2}$ & $\mathrm{~L}_{3}$ \\
\hline $\begin{array}{l}\text { nonhydroxylated } \\
\mathrm{TiO}_{2} \text { in contact }\end{array}$ & $1.0<0-2.5>$ & $1.06<2.5-4.2>$ & $1.60<4.2-7.0>$ \\
\hline $\begin{array}{l}\text { with bulk water } \\
\text { nonhydroxylated } \\
\mathrm{TiO}_{2} \text { in contact } \\
\text { with } 3.5 \mathrm{H}_{2} \mathrm{O} \\
\text { per surface }\end{array}$ & $1.0<0-2.5>$ & $1.07<2.5-4.2>$ & $1.43<4.2-\ldots>$ \\
\hline $\begin{array}{l}\mathrm{Ti}_{2} \mathrm{O}_{4} \text { unit } \\
\text { hydroxylated } \\
\mathrm{SnO}_{2} \text { in contact } \\
\text { with bulk water }\end{array}$ & $1.0<0-2.5>$ & $1.78<2.5-4.8>$ & $1.67<4.8-7.0>$ \\
\hline $\begin{array}{l}\text { hydroxylated } \\
\mathrm{SnO}_{2} \text { in contact } \\
\text { with } 4.0 \mathrm{OH} / \mathrm{H}_{2} \mathrm{O} \\
\text { per surface }\end{array}$ & $1.0<0-2.5>$ & $1.73<2.5-4.8>$ & $1.27<4.8-\ldots>$ \\
\hline $\mathrm{Sn}_{2} \mathrm{O}_{4}$ unit & & & \\
\hline
\end{tabular}

${ }^{a}$ The width of the corresponding layer $(\AA)$ is given in angle brackets. For $\mathrm{L}_{3}$ at limited hydration levels, only the boundary closer to the surface is shown.

exhibit much weaker axial ordering and essentially undetectable lateral ordering. On the other hand, $\mathrm{L}_{3}$ molecules on the hydroxylated surface (cassiterite) form a distinct peak at $6 \AA$, which suggests ordering of water molecules that differs considerably from bulk and the nonhydroxylated surface of rutile. Comparison with the simulations of metal oxides in contact with bulk water ${ }^{1,2}$ shows that the structure of water presented in Figure 12 is almost identical up to the distance of $6.5 \AA$ from the surface (i.e., the inner part of $\mathrm{L}_{3}$ ). This fact can be attributed to the dominant influence of the metal oxide surface structures compared to a relatively minor influence of the outer environment. The outer part of the $\mathrm{L}_{3}$ layer reaching up to $10 \AA$ from the surface can be characterized by gradually decreasing water density and average number of hydrogen bonds, and water in this layer is thus unable to form the typical short-range tetrahedral structure of bulk water.

In Table 4, we present the occupancy of the three surface layers, defined by integrating the density between minima in the axial oxygen profiles in the simulations with bulk water ${ }^{1,2}$ and also for the level of hydration of the samples in our experiments. As mentioned earlier, the first two layers $\left(\mathrm{L}_{1}\right.$ and $\mathrm{L}_{2}$ ) in the bulk water are practically identical to those found in this study for the limited adsorption from air. We also see that the total occupancy of the three layers in bulk water in contact with the (110) surface, $\left(\mathrm{L}_{1}+\mathrm{L}_{2}+\mathrm{L}_{3}\right)$, which is 3.66 for the nonhydroxylated rutile and 4.45 for the hydroxylated cassiterite, is quite similar to the actual estimated water coverages on our nanopowder surfaces obtained from the TGA/MS and WS/D isotherm data, which is 3.5 and 4.0 for $\mathrm{TiO}_{2}$ and $\mathrm{SnO}_{2}$, respectively. Thus, in our experiment, the hydration water forms almost 3 full layers on rutile and less than 3 full layers on cassiterite.

Dynamic structure factors derived from Fourier transformation of the MD simulated trajectories can be directly compared with the experimental signal measured on the DCS. Figure 13 shows the simulated DCS spectra for the nonhydroxylated rutile and hydroxylated cassiterite. One can see that one Lorentzian component is insufficient to adequately fit the simulated dynamic structure factors. At least two Lorentzian components 


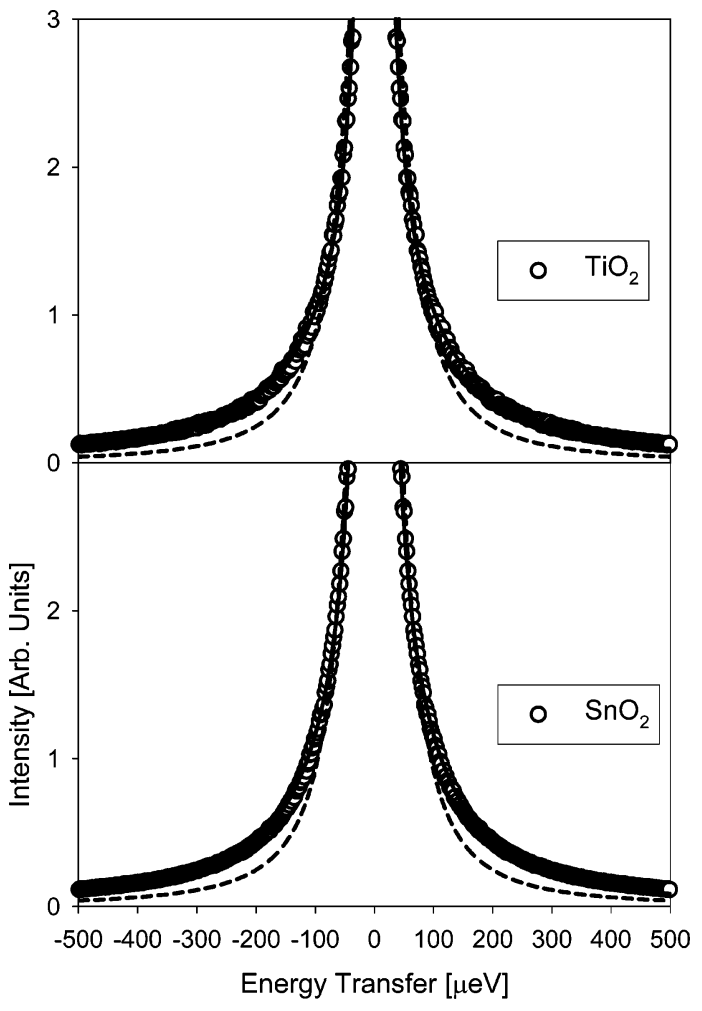

Figure 13. Dynamic structure factors for hydration water obtained in the MD simulation (symbols) fit with one Lorentzian component (dashed lines) and two Lorentzian components (solid lines).

TABLE 5: MD Results for the Relaxation Times (in ps) for the Systems of 3.5 (Rutile) and 4.0 (Cassiterite) $\left(\mathrm{OH} / \mathrm{H}_{2} \mathrm{O}\right.$ ) Molecules Per Surface Unit of $\mathrm{Me}_{2} \mathrm{O}_{4}$ Obtained from Simulated DCS Dynamic Structure Factors at $300 \mathrm{~K}^{a}$

\begin{tabular}{|c|c|c|c|c|}
\hline \multirow[b]{2}{*}{ system } & \multicolumn{2}{|c|}{$\mathrm{TiO}_{2}$} & \multicolumn{2}{|c|}{$\mathrm{SnO}_{2}$} \\
\hline & $\begin{array}{l}\text { DCS } \\
\text { "fast" }\end{array}$ & $\begin{array}{l}\text { DCS } \\
\text { "slow" }\end{array}$ & $\begin{array}{l}\text { DCS } \\
\text { "fast" }\end{array}$ & $\begin{array}{l}\text { DCS } \\
\text { "slow" }\end{array}$ \\
\hline $\begin{array}{l}\mathrm{H}_{2} \mathrm{O} \text { molecules } \\
\text { initially in } \mathrm{L}_{2}\end{array}$ & $4.96<1.65>$ & 39.53 & $5.63<1.87>$ & 38.67 \\
\hline $\begin{array}{l}\mathrm{H}_{2} \mathrm{O} \text { molecules } \\
\text { initially in } \mathrm{L}_{3}\end{array}$ & $4.88<1.63>$ & 32.89 & $5.51<1.84>$ & 37.27 \\
\hline All $\mathrm{H}_{2} \mathrm{O}$ molecules & $4.49<1.50>$ & 31.87 & $5.50<1.83>$ & 37.08 \\
\hline
\end{tabular}

${ }^{a}$ The data in angle brackets for the "fast" DCS component represent the relaxation times calculated as $\tau=\hbar / 3 \Gamma$ assuming purely rotational origin of this component.

corresponding to faster and slower diffusive motions on the DCS time scale are needed to obtain reasonable fits. The relaxation times for these two components are listed in Table 5. The relaxation times for the faster component are shown assuming either a purely translational $(\tau=\hbar / \Gamma$, where $\Gamma$ is the HWHM of the Lorentzian broadening) or rotational $(\tau=\hbar / 3 \Gamma)$ character, even though either of these models is likely an oversimplification, as we will discuss below. For both $\mathrm{TiO}_{2}$ and $\mathrm{SnO}_{2}$, the relaxation times compare well with those listed in Table 3 at $300 \mathrm{~K}$

To identify the contributions from particular layers that give rise to the DCS spectra, we divided the water molecules in the MD simulation into three groups, depending on where the molecules resided at the beginning of the simulation. During the simulation, the molecules could move between the layers, and thus, the resulting trajectories are averages that may include motion in different layers. Then we performed the same analysis for the surface hydroxyls or water molecules that started their

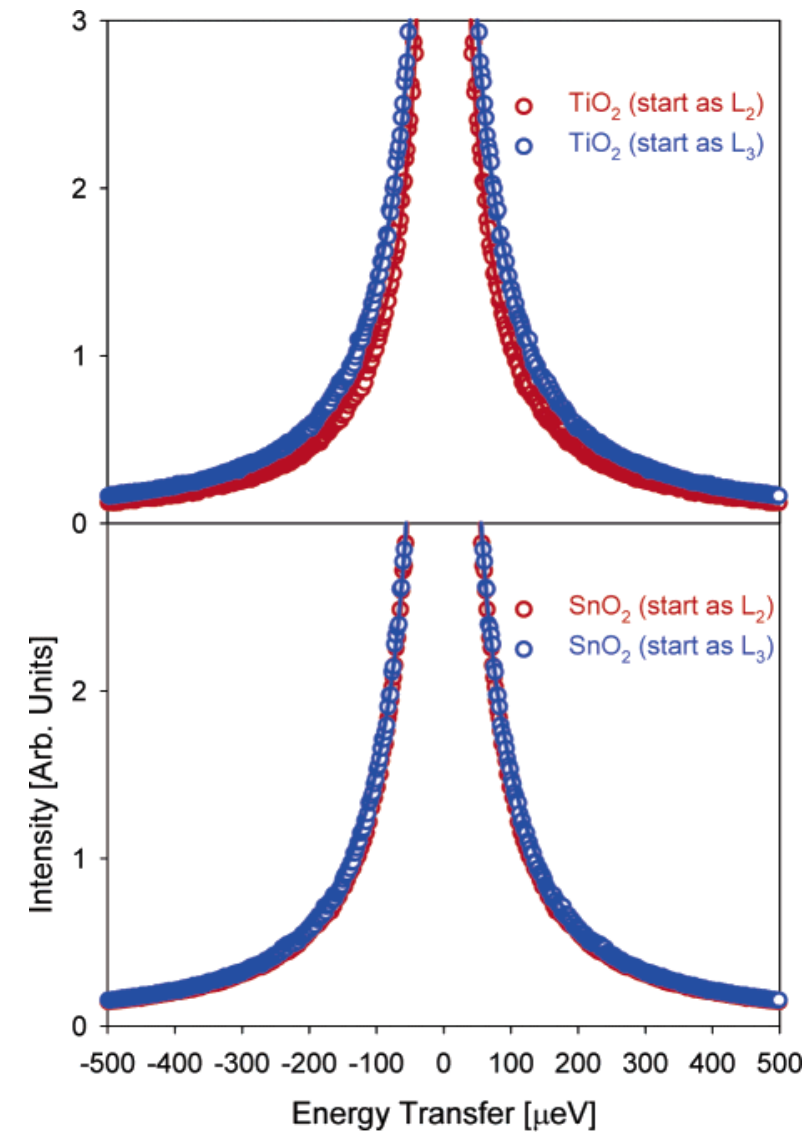

Figure 14. Dynamic structure factors obtained in the MD simulation (symbols) for the hydration water molecules that originally belong to $\mathrm{L}_{2}$ or $\mathrm{L}_{3}$ fit with two Lorentzian components (solid lines).

trajectories in the $\mathrm{L}_{1}, \mathrm{~L}_{2}$, and $\mathrm{L}_{3}$ layers and compared their $\mathrm{MD}$ dynamic structure factors, presuming that even if molecules could change layers during the time span of the simulation (1 $\mathrm{ns}$ ), the results will still reflect their initial position. We found that the $\mathrm{L}_{1}$ protons contribute only to the elastic signal and that there was no exchange of protons between the $\mathrm{L}_{1}$ and outer layers. Only the water molecules that resided in $\mathrm{L}_{2}$ or $\mathrm{L}_{3}$ in the beginning of the simulation contribute to the signal on the DCS time scale (Figure 14). The somewhat stronger signal in Figure 14 originating from the $\mathrm{L}_{3}$ molecules compared to the $\mathrm{L}_{2}$ molecules (especially for rutile) suggests that the diffusion motions with the residence times in the range of 1 to $100 \mathrm{ps}$ originate mostly from the outer layer $\mathrm{L}_{3}$. One can arrive at the same conclusion by means of comparing the average residence times obtained for the molecules that started their trajectory either in $\mathrm{L}_{2}$ or $\mathrm{L}_{3}$ as listed in Table 5. At the same time, the presence of the QENS signal of almost the same strength and width in the simulated data for the originally $\mathrm{L}_{2}$ group of molecules indicates that some or all of these molecules migrate to the $\mathrm{L}_{3}$ layer (and vice versa) on the $1 \mathrm{~ns}$ simulation time scale.

We also attempted longer simulations spanning up to $10 \mathrm{~ns}$ in order to investigate the origin of the QENS signal on the time scale of the HFBS. Even though this time span proved to be insufficient, yielding strong oscillations in the simulated dynamic structure factors due to Fourier transformation of the trajectories that have not fully decayed at $10 \mathrm{~ns}$, we found that no HFBS signal came from the $\mathrm{L}_{1}$ protons, and therefore, these molecules contributed only to the elastic signal, even on the HFBS time scale. The strongest signal appears to come from the $\mathrm{L}_{2}$ molecules and somewhat weaker signal from the $\mathrm{L}_{3}$ 
molecules. Since the simulation spanned approximately $10 \mathrm{~ns}$, molecules in the $\mathrm{L}_{2}$ and $\mathrm{L}_{3}$ layers could be expected to have enough time to exchange between the layers many times. These results suggest that the motions with the residence times in the range of $100-1000 \mathrm{ps}$ take place in the $\mathrm{L}_{2}$ layer.

The slower diffusion components on the time scale of the DCS measurement is of translational origin, that is, for a molecule involved, at least three hydrogen bonds break simultaneously, and the molecule rearranges itself to form the new bonds with different neighbors. The faster diffusion component on the time scale of the DCS measurement involves the motion of water molecules with less than three hydrogen bonds broken at a given time. The water molecule involved in this type of motion does not change all of its neighbors simultaneously. It is customary to describe this motion as a hindered rotation, ${ }^{26}$ for which the dominating QENS broadening term has a HWHM of $\hbar / 3 \tau_{R}$, where $\tau_{R}$ is the time between the rotational jumps. However, the actual motion of water molecules on the picosecond time scale is more complex than pure rotation. In particular, our MD results show that the centers of mass of water molecules exhibit two dynamic components similar to those of protons in the water molecules. For the translational diffusion on the time scale of tens of picoseconds, one would expect the center of mass and protons of a water molecule to show the same dynamics. However, should the motion on the picosecond time scale be purely rotational, this picosecond component would exhibit itself in the dynamics of protons but not the center of mass. On the other hand, it is unlikely that this fast picosecond dynamics is purely translational. In fact, our MD simulation yields the following rotational diffusion coefficients for the water molecules of $\mathrm{L}_{3}$ : for $\mathrm{TiO}_{2}, D_{\mathrm{R}}=0.09 \mathrm{ps}^{-1}$ (corresponding to $\tau_{\mathrm{R}}=1.85 \mathrm{ps}$ ), and for $\mathrm{SnO}_{2}, D_{\mathrm{R}}=0.14 \mathrm{ps}^{-1}$ (corresponding to $\tau_{\mathrm{R}}=1.19 \mathrm{ps}$ ). The values for the rotational relaxation times $\tau_{\mathrm{R}}$ are in an excellent agreement with those listed in Table 3 for $300 \mathrm{~K}$. Following the common practice, we call the dynamics of the water molecules on the picosecond time scale within the cage formed by the neighboring molecules rotational, even though this complex dynamics is neither purely rotational not translational.

3.3. Discussion: Difference between Hydration Water in Rutile and Cassiterite. As far as the dynamic behavior on the time scale of the HFBS is concerned, we want to emphasize that the fragile-to-strong transition that we observed for hydration water in rutile but not in cassiterite is not an artifact caused by using Debye-type exponential relaxation functions in the time space (that yields a Lorentzian broadening in the energy space) instead of more complex stretched exponential relaxation functions $^{31}$ (that is, using $\exp [-(t / \tau)]$ instead of $\exp \left[-(t / \tau)^{\beta}\right]$ ). Previously we have found $d^{7,8}$ that even for the water molecules of the inner hydration layer, which experience a greater variety of local environments and are thus expected to exhibit more stretched behavior compared to the molecules of the outer hydration layer, almost Debye-like relaxation functions characterized by the stretch factors $\beta$ exceeding $0.8-0.9$ were obtained. Besides, when either stretched or regular exponential relaxation functions were used in the data analysis of hydration water in $\mathrm{CeO}_{2}$, both types of relaxation functions yielded the same fragile-to-strong transition temperature of $215 \mathrm{~K}$, indicating that either type of the relaxation function was suitable for pinpointing this transition. Furthermore, the presence of this transition in the current experimental data can be inferred from a simple visual analysis of the data for $\mathrm{TiO}_{2}$ shown in Figure 7. The data clearly exhibit the most dramatic change in the width of the QENS signal due to abruptly increasing residence time between 240 and $220 \mathrm{~K}$, which is indicative of super-Arrhenius behavior. The trend of the rapidly increasing residence time, however, does not persist at 210 and $200 \mathrm{~K}$, indicating that super-Arrhenius behavior does not extrapolate below $220 \mathrm{~K}$ and thus implying the presence of the fragile-to-strong transition between 220 and $210 \mathrm{~K}$.

As we have discussed above, both the QENS data and MD simulations strongly suggest the relatively lower occupancy for the layer $\mathrm{L}_{3}$ in $\mathrm{SnO}_{2}$ compared to $\mathrm{TiO}_{2}$. A weaker QENS signal obtained from the hydrated cassiterite on the DCS (which probes the dynamics of the $\mathrm{L}_{3}$ layer) is likely due to the lower ratio of $\mathrm{L}_{3} /\left(\mathrm{L}_{1}+\mathrm{L}_{2}+\mathrm{L}_{3}\right)$, which is 0.41 for rutile and 0.32 for cassiterite at the hydration levels of our experiment (see Table 4). In contrast, the ratio of $\mathrm{L}_{2} / \mathrm{L}_{1}$ is 1.73 for cassiterite and 1.07 for rutile at the hydration levels of our experiment, and $\mathrm{L}_{2}$ also exhibits a more complex bonding environment on cassiterite, as indicated from the broad and asymmetrical axial density profile (Figure 12). This asymmetrical distribution is shown by the simulations to arise from two types of water in $L_{2}$ on cassiterite, one type forming strong hydrogen bonds with bridging hydroxyl groups and a second type, lying further from the surface, which forms H-bonds with the first type and with terminal hydroxyl groups of $\mathrm{L}_{1}$. These two factors (higher coverage and more complex structure of $\mathrm{L}_{2}$ on cassiterite) help explain the nearly equal HFBS signal intensities of rutile and cassiterite, as shown in Figure 7.

Not only the relatively lower occupancy of $\mathrm{L}_{3}$ in hydrated cassiterite compared to the occupancy of $\mathrm{L}_{3}$ in hydrated rutile explains the difference in the strength of the QENS DCS signal, but also it provides a possible explanation for the lack of noticeable fragile-to-strong transition in hydration water in $\mathrm{SnO}_{2}$ since the water molecules in the layer $\mathrm{L}_{2}$ in cassiterite may experience a less bulk-like environment compared to the water molecules in the layer $\mathrm{L}_{2}$ in rutile. Thus, a possible reason why the super-Arrhenius behavior and the fragile-to-strong transition is observed in hydration water in $\mathrm{TiO}_{2}$ but not in $\mathrm{SnO}_{2}$ may be due to more "three-dimensional" nature of the hydration water in the former oxide. The strength of interaction of the water molecules with the surface may be another important factor. Finally, the different behavior of the $\mathrm{L}_{2}$ layer maybe due to the nature of the $\mathrm{L}_{1}$ layer $\left(\mathrm{H}_{2} \mathrm{O}\right.$ in rutile vs $\mathrm{OH}$ in cassiterite).

Looking at Figure 11, one can notice the displacements of near-surface atoms in $\mathrm{TiO}_{2}$, which is a visible manifestation of the much higher polarizability of rutile compared to cassiterite. Sverjensky and collaborators have shown ${ }^{32,33}$ from an analysis of the sorption of electrolyte ions on metal oxide surfaces that there appears to be a fundamental difference in the structure of the interface between aqueous solutions and oxides with high bulk dielectric constants ( $\kappa^{\prime}$, dimensionless) such as magnetite $\left(\mathrm{Fe}_{3} \mathrm{O}_{4}\right)$ and the $\mathrm{TiO}_{2}$ polymorphs rutile and anatase $\left(\kappa^{\prime}=10^{4}\right.$, 120 , and 21 , respectively) as compared to the interface with low-bulk dielectric phases such as goethite $(\mathrm{FeOOH})$, quartz $\left(\alpha-\mathrm{SiO}_{2}\right)$, and corundum $\left(\alpha-\mathrm{Al}_{2} \mathrm{O}_{3}\right)$ with $\kappa^{\prime}=11.7,4.6$, and 10.4 , respectively. Application of the triple-layer site complexation model ${ }^{32,33}$ suggests that low- $\kappa^{\prime}$ oxides exhibit thick layers (up to $4 \AA$ ) of water between the oxide surface and the sorption sites of dissolved cations, and these cations appear to be fully hydrated. On the other hand, high- $\kappa^{\prime}$ solids are postulated ${ }^{33}$ to have only a thin layer $(1-2 \AA)$ of sorbed water which is interpenetrated by sorbing cations that can approach the surface at distances approaching their unhydrated crystallographic radii. Our own synchrotron X-ray, ab initio and classical simulation studies of rutile and cassiterite ${ }^{1,2,34}$ are consistent with this suggestion. All cations studied on rutile (110) surfaces sorb in 
direct contact with $\mathrm{L}_{1}$ oxygen atoms, at distances consistent with their bare crystallographic radii, and there is little evidence for any type of ordering of the solvent beyond layer three. This is evident in Figure 12, which also indicates at least one additional ordered layer of water beyond $\mathrm{L}_{3}$ on the cassiterite surface. Rutile, $\mathrm{ZrO}_{2}$ and $\mathrm{CeO}_{2}\left(\kappa^{\prime}=120,22\right.$, and 17 , respectively $\left.{ }^{32,35}\right)$ all exhibit super-Arrhenius behavior of water presumed to reside in $\mathrm{L}_{2}$, as revealed by this and previous ${ }^{7,8}$ QENS studies using the HFBS, whereas cassiterite with a bulk dielectric constant between quartz and corundum $\left(\kappa^{\prime}=9\right)$ does not exhibit superArrhenius behavior or a fragile-strong transition within the temperature range investigated. Thus, such contrasting behavior of the inner hydration water may be a common feature of lowversus high-bulk-dielectric phases. This difference in bulk dielectric properties may also influence the binding strength of hydration waters, which is higher for cassiterite than for rutile, as well as the greater tendency for dissociative water sorption in the inner layer on cassiterite versus rutile. ${ }^{36}$

Other differences in the nature of the crystalline phase may also contribute to the contrasting water sorption structure and dynamics. The higher electronegativity of tin (1.96) versus titanium (1.54), as well as the differing polarizabilities of the $\mathrm{Me}^{\mathrm{IV}}$ ions is presumably associated with the differing dielectric properties of the isostructural oxides and may promote dissociative versus associative adsorption of $\mathrm{L}_{1}$, which strongly influences the dynamic and structural properties of $\mathrm{L}_{2}$ and $\mathrm{L}_{3}$. Also, somewhat larger lattice parameters of cassiterite result in a larger lateral separation between the terminal and bridging sites, which inhibits hydrogen bonding between a water molecule at the terminal site and a bare oxygen atom at the bridging site. The same larger spacing permits a closer approach of $\mathrm{L}_{2}$ water molecules to the surface plane of cassiterite, resulting in stronger hydrogen bonds. These concepts will be tested by further high-resolution QENS studies of low-bulk-dielectric phases using the HFBS.

One intriguing question that remains to be answered is as follows: Does the temperature dependence of the relaxation time for the outer hydration layer in $\mathrm{TiO}_{2}$ show a fragile-tostrong transition similar to the one exhibited by the inner hydration layer in $\mathrm{TiO}_{2}$ ? On the one hand, the dynamics of the translational component for the molecules of the outer hydration layer seems to be Arrhenius in the temperature range accessible in the current experiment. On the other hand, a neutron measurement using a spectrometer with energy resolution higher than that of our DCS measurement and the dynamic range larger than that of the HFBS would allow monitoring the dynamics of the outer hydration water molecules down to lower temperatures. Such a measurement may reveal super-Arrhenius temperature dependence for the outer hydration layer. For example, in an experiment on hydrated $N$-acetyl-leucine-methylamide, ${ }^{37}$ the dynamics of water associated with the strongly bound inner hydration layer was strongly super-Arrhenius, whereas for the weaker bound external hydration layer, the dynamics was also super-Arrhenius, albeit only weakly. Thus, the character of the temperature dependence of the dynamics of the outer hydration layer should be addressed in the future studies.

\section{Conclusion}

We have studied the dynamics and structure of hydration water in $\mathrm{TiO}_{2}$ and $\mathrm{SnO}_{2}$ nanopowders exhibiting the rutile crystal structure with the (110) face predominant, using quasielastic neutron spectrometers capable of probing different time scales of the hydration water diffusion and the MD simulations. In both systems, the QENS data indicated three diffusion compo- nents, and the MD simulations reveal three structurally distinct layers on each surface, including $\mathrm{L}_{1}$ chemisorbed water molecules or hydroxyl groups and $\mathrm{L}_{2}$ and $\mathrm{L}_{3}$ inner and outer hydration water molecules. The fastest QENS component on the time scale of picoseconds has been attributed to the diffusion process involving the motion of $\mathrm{L}_{3}$ (and probably $\mathrm{L}_{2}$ ) water molecules inside the cage formed by the neighboring water molecules. Even though this diffusion component is typically called rotational, the MD results suggest that it incorporates both rotational and translational motions. The next component on the time scale of tens of picoseconds has been assigned to translational diffusion motions of the more loosely bound $\mathrm{L}_{3}$ water molecules. The slowest component on the time scale of hundreds of picoseconds to a nanosecond has been attributed to spatially restricted translational diffusion motions of the more tightly bound water molecules of the $\mathrm{L}_{2}$ inner hydration layer, which is in direct contact with immobile $\mathrm{L}_{1}$ species on the oxide surface. The species that make up the $\mathrm{L}_{1}$ layer are either $\mathrm{H}_{2} \mathrm{O}$ molecules on the nonhydroxylated surface of rutile or the $\mathrm{OH}$ groups on the hydroxylated surface of cassiterite.

For the $\mathrm{SnO}_{2}$ sample with the lower hydration level compared to the $\mathrm{TiO}_{2}$ sample, we have observed a significantly reduced fraction of the QENS signal representing the translational mobility of the outer hydration layer $\left(\mathrm{L}_{3}\right)$ water molecules. For the hydrated $\mathrm{TiO}_{2}$ sample, the temperature dependence of the diffusion relaxation time for the two faster components was an Arrhenius-type, whereas for the slowest component that represents the dynamics of $\mathrm{L}_{2}$, it was super-Arrhenius and could be fit in the temperature range of 280 to $220 \mathrm{~K}$ using a VFT law with a glass transition temperature of $(201 \pm 4) \mathrm{K}$. Between 220 and $210 \mathrm{~K}$, there was a crossover in the temperature dependence indicative of the fragile-to-strong transition in the hydration water. Qualitatively different temperature dependence for the fast and slow translational components supports the claim that these components originate from different types of hydration water molecules. The more strongly bound water molecules $\left(\mathrm{L}_{2}\right)$ form more hydrogen bonds and exhibit slow relaxation dynamics characterized by super-Arrhenius behavior at temperatures above the fragile-to-strong transition. The more loosely bound outer water molecules $\left(\mathrm{L}_{3}\right)$ form fewer hydrogen bonds and thus exhibit faster surface-diffusion-type dynamics with Arrhenius temperature dependence. The two faster diffusion components for hydrated $\mathrm{SnO}_{2}$ showed very little temperature dependence in the probed temperature region of 320 and $280 \mathrm{~K}$. Remarkably, the slowest diffusion component for $\mathrm{SnO}_{2}$ associated with the $\mathrm{L}_{2}$ layer could be fit with Arrhenius temperature dependence and showed no indication of super-Arrhenius behavior and fragile-to-strong transition.

We attributed this difference between the hydration water dynamics in $\mathrm{TiO}_{2}$ and $\mathrm{SnO}_{2}$ primarily to the nature of $\mathrm{L}_{1}$, which tends toward associative adsorption of a water molecule on the 5-fold metal ion in rutile and toward dissociation to bridging and terminal hydroxyl groups on cassiterite. This difference in $\mathrm{L}_{1}$ structure strongly influences the distribution and dynamics of the hydration water molecules between the inner and the outer hydration layers. These variations in the spatial arrangement of the surface water molecules likely originate from both the geometrical factors such as the difference in the lattice constants and the strength of the interaction between the water molecules and the surface related to the bulk dielectric constant and metal atom electronegativity and polarizability of the isostructural oxides. Thus, not only the overall hydration level, but also the strength of the interaction with the surface and the distribution of the surface water molecules among the hydration layers may 
determine the qualitative character of the temperature dependence of the hydration water diffusivity.

Acknowledgment. The authors are thankful to D. Abernathy and G. Ehlers for a critical reading of the manuscript. The authors acknowledge that the reported research used the resources of the Computing Center for Research and Education at Vanderbilt University. Utilization of the DAVE package for the data analysis is acknowledged. This work utilized NCNR neutron scattering facilities supported in part by the National Science Foundation under Agreement No. DMR-0454672. This work was supported by the U.S. Department of Energy, Office of Basic Energy Sciences, Division of Chemical Sciences, Geosciences and Biosciences through the project "Nanoscale Complexity at the Oxide/Water Interface" (ERKCC41) and by the Spallation Neutron Source (SNS) managed by UT-Battelle, LLC under Contract No. DE-AC05-00OR22725 for the U.S. Department of Energy. Certain commercial equipment, instruments, or materials are identified in this paper to foster understanding. Such identification does not imply recommendation or endorsement by the National Institute of Standards and Technology, nor does it imply the materials or equipment identified are necessarily the best available for the purpose.

\section{References and Notes}

(1) Predota, M.; Bandura, A. V.; Cummings, P. T.; Kubicki, J. D.; Wesolowski, D. J.; Chialvo, A. A.; Machesky, M. L. J. Phys. Chem. B 2004, 108, 12049.

(2) Vlcek, L.; Zhang, Z.; Machesky, M. L.; Fenter, P.; Rosenqvist, J.; Wesolowski, D. J.; Anovitz, L. M.; Predota, M.; Cummings, P. T Langmuir, in press.

(3) Boerio-Goates, J.; Li, G.; Li, L.; Walker, T. F.; Parry, T.; Woodfield, B. F. Nano Lett. 2006, 6, 750 .

(4) Kuroda, Y.; Kittaka, S.; Takahara, S.; Yamaguchi, T.; BellisentFunel, M.-C. J. Phys. Chem. B 1999, 103, 11064.

(5) Takahara, S.; Kittaka, S.; Mori, T.; Kuroda, Y.; Yamaguchi, T.; Shibata, K. J. Phys. Chem. B 2002, 106, 5689.

(6) Mamontov, E. J. Chem. Phys. 2004, 121, 9087.

(7) Mamontov, E. J. Chem. Phys. 2005, 123, 024706.

(8) Mamontov, E. J. Chem. Phys. 2005, 123, 171101.

(9) Ridley, M. K.; Machesky, M. L.; Palmer, D. A.; Wesolowski, D. J. Colloids Surf. A 2002, 204, 295.

(10) Rosenqvist, J. et al. manuscript in preparation.
(11) Webb, P. A.; Orr, C. Analytical Methods in Fine particle Technology; Micromeritics Instrument Corp.: Norcross, GA, 1997.

(12) Brunauer, S.; Skalny, J.; Bodor, E. E. J. Colloid Interface Sci. 1969, 30,546 .

(13) Copley, J. R. D.; Cook, J. C. Chem. Phys. 2003, 292, 477.

(14) Meyer, A.; Dimeo, R. M.; Gehring, P. M.; Neumann, D. A. Rev. Sci. Instrum. 2003, 74, 2759.

(15) Berendsen, H. J.; Grigera, J. R.; Straatsma, T. P. J. Phys. Chem. 1987, 91, 6269 .

(16) Sorensen, J. M.; Hura, G.; Glaeser, R. M.; Head-Gordon, T. J. Chem. Phys. 2000, 113, 9149.

(17) Bandura, A. V.; Kubicki, J. D. J. Phys. Chem. B 2003, 107, 11072.

(18) Bandura, A. V.; Sofo, J.; and Kubicki, J. D. J. Phys. Chem. B 2006, $110,8386$.

(19) Zhang, Z.; Fenter, P.; Sturchio, N. C.; Bedzyk, M. J.; Machesky, M. L.; Wesolowski, D. J. Surf. Sci., submitted.

(20) Lindan, P. J. D. Chem. Phys. Lett. 2000, 328, 325.

(21) Bates, S. P. Surf. Sci. 2002, 512, 29.

(22) Batzill, M.; Diebold, U. Prog. Surf. Sci. 2005, 79, 47.

(23) Yeh, I. -C.; Berkowitz, M. L. J. Chem. Phys. 1999, 111, 3155.

(24) Ryckaert, J. P.; Ciccotti, G.; Berendsen, H. J. C. J. Comput Phys. 1977, 23, 327.

(25) Sears, V. F. Can. J. Phys. 1966, 44, 1299; Sears, V. F. Can. J. Phys. 1966, 45, 237.

(26) Teixeira, J.; Bellissent-Funel, M.-C.; Chen, S. H.; Dianoux, A. J. Phys. Rev. A 1985, 31, 1913.

(27) Faraone, A.; Liu, L.; Mou, C.-Y.; Yen, C.-W.; Chen, S.-H. J. Chem. Phys. 2004, 121, 10843.

(28) Chen, S.-H.; Liu, L.; Fratini, E.; Baglioni, P.; Faraone, A.; Mamontov, E. Proc. Natl. Acad. Sci. 2006, 103, 9012.

(29) Chen, S.-H.; Liu, L.; Chu, X.; Zhang, Y.; Fratini, E.; Baglioni, P.; Faraone, A.; Mamontov, E. J. Chem. Phys. 2006, 125, 171103.

(30) Mamontov, E.; Burnham, C. J.; Chen, S.-H.; Moravsky, A. P.; Loong, C.-K.; de Souza, N. R.; Kolesnikov, A. I. J. Chem. Phys. 2006 124, 194703.

(31) Zanotti, J.-M.; Bellissent-Funel, M.-C.; Chen, S. H. Phys. Rev. E 1999, 59, 3084

(32) Sahai, N.; Sverjensky, D. A. Geochim. Cosmochim. Acta 1997, 61, 2827.

(33) Sverjensky, D. A. Geochim. Cosmochim. Acta 2001, 65, 3643.

(34) Zhang, Z.; Fenter, P.; Cheng, L.; Sturchio, N. C.; Bedzyk, M. J.; Predota, M.; Bandura, A. V.; Kubicki, J. D.; Lvov, S. N.; Cummings, P. T.; Chialvo, A. A.; Ridley, M. K.; Benzeth, P.; Anovitz, L. M.; Palmer, D.

A.; Machesky, M. L.; Wesolowski, D. J. Langmuir 2004, 20, 4954.

(35) Shannon, R. D. J. Appl. Phys. 1993, 73, 348.

(36) Bandura, A. V.; Sofo, J.; Kubicki, J. D. J. Phys. Chem. B (in preparation).

(37) Russo, D.; Murarka, R. K.; Hura, G.; Verschell, E.; Copley, J. R. D.; Head-Gordon, T. J. Phys. Chem. B 2004, 108, 19885. 